Sādhanā Vol. 40, Part 2, April 2015, pp. 335-350. (C) Indian Academy of Sciences

\title{
A computerized loop based approach for identification of isomorphism and type of mobility in planar kinematic chains
}

\author{
MANOJ K LOHUMI ${ }^{1,2, *}$, AAS MOHAMMAD ${ }^{1}$ and \\ IRSHAD A KHAN ${ }^{1}$ \\ ${ }^{1}$ Department of Mechanical Engineering, Jamia Millia Islamia University, \\ New Delhi 110 025, India \\ ${ }^{2}$ Department of Mechanical Engineering, Galgotias College of Engineering and \\ Technology, Knowledge Park-2, Greater Noida 201 306, India \\ e-mail: mlohumi@gmail.com
}

MS received 1 September 2012; revised 18 September 2014; accepted 12 December 2014

\begin{abstract}
Some new invariants like chain string, link identification string, loop participation of joint frequency string and loop size frequency string of simple jointed kinematic chains are presented. The first step of the proposed method is to identify all possible loops of a kinematic chain and then these new invariants are developed. A modified loop-joint approach is proposed in this work as compared to the previous work in literature where loop-link matrix is formulated to search all the loops present in a kinematic chain. A computer program has been developed for formulating loop-joint matrix of kinematic chain and its all invariants. This method takes into consideration all the loops present, associated joints and links and is able to test isomorphism among kinematic chains and their inversions and also to detect type of mobility of multi degree of freedom kinematic chains. The proposed method is successfully tested for all kinematic chains upto five independent loops having any number of degree of freedom and no counter example is found. The detailed results of 9-link, $\mathrm{M}=2$ (mobility) and 10 link, $\mathrm{M}=3$ kinematic chains are provided with five types of mobility and results are in accordance with the results published in literature. The method is also explained with the help of some complex examples and presented in this paper.
\end{abstract}

Keywords. Kinematic chain; distinct mechanisms; mobility; independent loops; loop-joint matrix.

*For correspondence 


\section{Introduction}

Structural synthesis (Rajesh \& Linda 2006; Eric \& Chris 2005) of kinematic chains has been a subject of research from last several decades. It includes the enumeration of kinematic chains and mechanisms from a set of given link and degree of freedom without any duplication. The identification of duplication or isomorphism among kinematic chains has been found tedious and troublesome job by the researchers in the past and various methods have been proposed for it. The characteristic polynomial methods (Uicker \& Raicu 1975; Yan \& Hall 1981, 1982; Mruthyunjaya 1984a, b, c) proposed by the researchers are efficient but some counter examples (Mruthyunjaya \& Balasubramanzan 1987) have been reported. Various code based (Ambekar \& Agrawal 1986, 1987; Tang and Liu 1993) and distance and loop based (Rao \& Varada 1991; Rao \& Rao 1992a, b; Huafeng \& Zhen 2007; Ding et al 2008; Rao \& Raju 2000) approaches are also proposed by the researchers in which distance among the links or joints is the basis of characterization of kinematic chains. The hamming number (Rao \& Varada 1991; Rao \& Rao 1992a, b) approach is computationally complex as in so many cases computation of higher order hamming strings is required to reach the final result. Some artificial intelligence based methods such as neural networks (Kong et al 1999), genetic algorithm (Rao 2000a) and fuzzy logic (Rao 2000b) are also proposed but these methods are generally very complex and time consuming as they require a lot of iterations to reach the final result. The loop based methods (Huafeng \& Zhen 2007; Ding et al 2008; Rao \& Raju 2000) are also reported by the researchers in which all the loops of a kinematic chain are the basis of characterization of kinematic chains and mechanisms. The loops of kinematic chain identified by Rao \& Raju (2000) are found to be a combination of loops and meshes, not loops alone and it also fails to identify distinct mechanism derived from 10 link 3-DOF kinematic chains (in chain number 61, 62, 63, 64 and 65 of Mruthyunjaya (2003) link 6 and 7 are not equivalent links but this method fails to identify it.). Ding et al (2008) proposed the loop based canonical degree sequence for isomorphic identification of kinematic chains. In this method, there are various steps for isomorphism identification namely; identification of all the loops of kinematic chain, formation of canonical degree sequence, relabelling of kinematic chain, forming adjacency matrix and finally matching it. The whole process looks lengthy and requires a lot of computational effort and finally a kinematic chain may have more than one maximum perimeter degree sequence. Mruthyunjaya (2003) in his review paper has summarized the efficiency and limitations of various methods dealing with this problem. Irrespective of so many available methods, the isomorphism identification among kinematic chains remains a hot area for research in last few decades.

The multi degree of freedom kinematic chains have potential applications in the area of robot design. For this, there is always a need to classify the kinematic chains on the basis of type of mobility or degree of freedom. Many researchers (Agrawal \& Rao 1987; Tischler et al 1995; Mruthyunjaya 2003) in the past have successfully dealt this problem either at enumeration stage or a specific method has been developed for it. In addition to isomorphism identification, the proposed method is also able to classify multi degree of freedom kinematic chains on the basis of type of mobility. Five types of mobility are identified and discussed and the results are in accordance with Agrawal \& Rao (1987).

In the present work, a loop-joint matrix is formulated with the help of a computer program which is capable (i) detecting isomorphism among kinematic chains with the help of chain string (CS), (ii) find DM derived from a kinematic chain with the help of link identification string (LIS), (iii) detect type of mobility with the help of loop participation of joints frequency string (LPOJFS) and loop size frequency string (LSFS). 


\section{Definitions}

\subsection{Loop}

A loop is any closed path through a kinematic chain in which no link or joint is encountered more than once e.g., the loop $(5,6,7,8,9,10)$ of figure 1a. The loop of a kinematic chain also represents the connectivity among the links.

\subsection{Independent loop (IL)}

The inner loop of kinematic chain inside which there is no other closed loop is known as independent loop. The numbers of independent loops of a kinematic chain are evaluated by the Euler's theorem

$$
I L=m-n+1,
$$

where ' $m$ ' is the number of joints and ' $n$ ' is number of links.

For most of the planar kinematic chains the independent loops can be determined by visual inspection and are arbitrarily selected. Each independent loop must contain at least one link or joint which other independent loops do not contain and each link and/or joint must appear in at least on of the independent loops. For cross linked kinematic chains, the independent loops are selected by the same approach as mentioned by Rao \& Raju (2000). The number of links or joints participating in a loop is known as loop size (LS).

\subsection{Sub-Loops}

The loops formed by the combination of independent loops are termed as sub-loops. For example, there are three independent loops in 10 link, $\mathrm{M}=3$ kinematic chain of figure 1a, namely loop-1, loop-2 and loop-3 (denoted by loop number inside the circle). The sub-loops formed by these loops will be loop (1-2), loop (1-3), loop (2-3) and loop (1-2-3). This theory has been explained by authors in their earlier work but all of the above said loops may or may not exists e.g., the kinematic chain of figure 1a, loop (1-3) does not exist. As it is not always easy to identify sub-loops by visual inspection especially for larger complex and cross linked

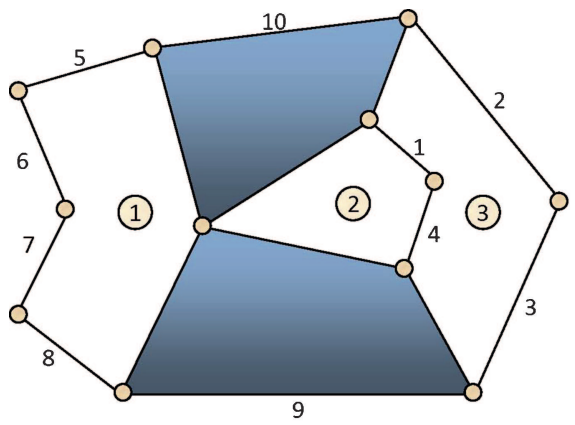

(a)

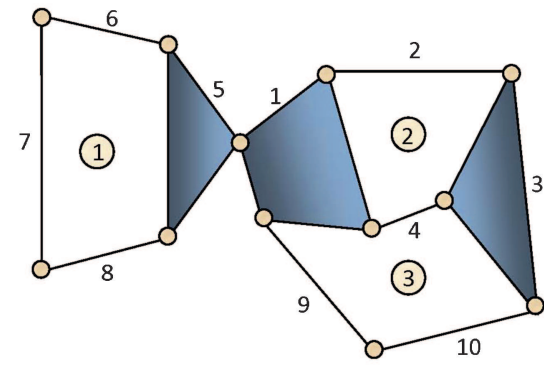

(b)

Figure 1. Two $10 \operatorname{link} \mathrm{M}=3$ kinematic chain. 
kinematic chains therefore a methodology has been developed to identify them in the following sections.

\subsection{Loop-Joint matrix}

In the present method, a loop-joint matrix is prepared for identification of all sub-loops and some new invariants of kinematic chain. Previous work on loop identification (Rao \& Raju 2000) is mainly based on loop-link relations where links associated with loop are identified. The major drawback of previous method is that it does not take into consideration all the joints of kinematic chain (figures $2 \& 3$ ). For example, the 11 link, $M=4$, kinematic chain of figure 2 there are three independent loops namely, $(1,2,3,4),(6,7,8,10,9)$ and $(6,9,10,11)$. These three independent loops do not contain link ' 5 ' and joints (4-5) and (5-6). Now, if we develop a looplink matrix, the link ' 5 ' will be included in loop-link matrix but the connectivity of the link ' 5 ' (i.e., joints (4-5) and (5-6)) will not be clear as it is not included in any of the independent

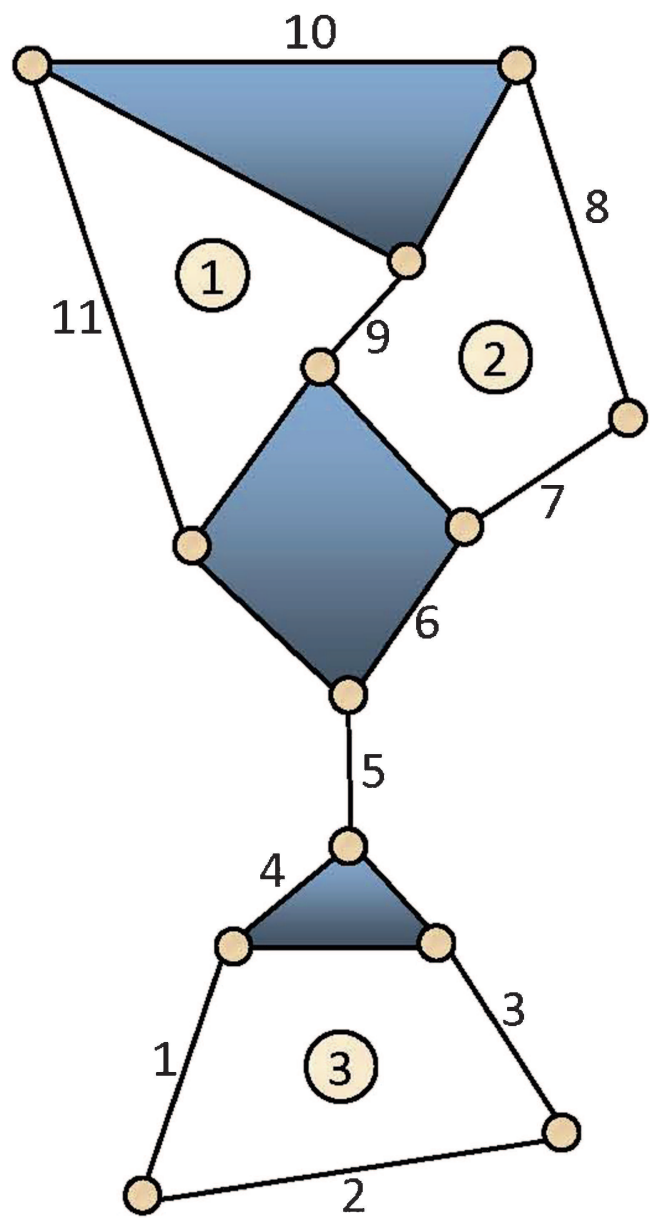

Figure 2. An 11 link $M=4$ kinematic chain. 


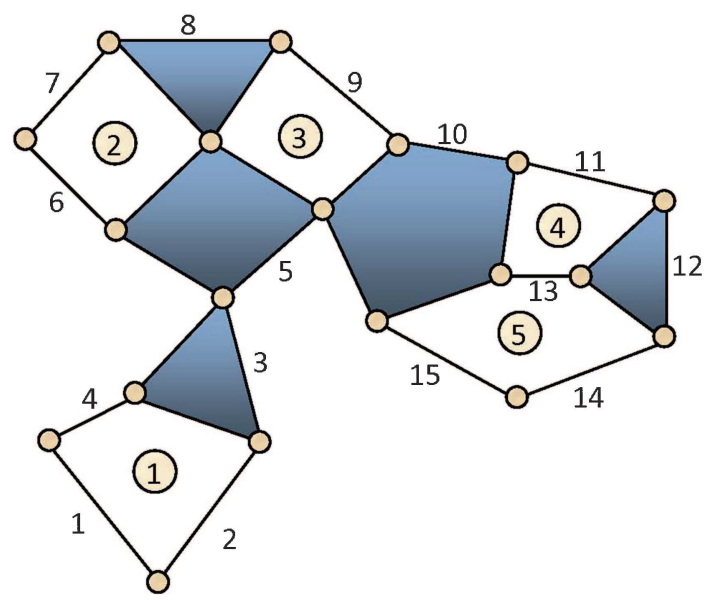

Figure 3. A 15 link $\mathrm{M}=4$ kinematic chain.

loops. But if a loop-joint matrix developed, it will include all the links and joints automatically. Hence the loop-link matrix representation of kinematic chain looks erroneous. In the present work, three parameter are included to represent a kinematic chain in the form of loop-joint matrix i.e., links, connectivity among the links (joints) and finally loops formed due to these connectivities.

The loop-joint matrix is prepared with the help of a computer program in the following steps and this can be understood with the help of examples.

Step 1: Identify all the independent loops of the given kinematic chain. For kinematic chain of figure $1 \mathrm{a}$, the independent loops are $(5,6,7,8,9,10),(1,4,9,10)$ and $(1,4,9,3,2,10)$.

Step 2: Identify all the joints associated with the kinematic chain with the help of independent loops and loop-joint matrix is formed in such a way that if any joint is in the loop, it has a value equal to ' 1 ' otherwise ' 0 '. Hence loop-joint matrix is a combination 1 's and 0 's. If any joint is not included in any of the independent loops, it is accommodated separately in the loop-joint matrix.

Step 3: As all the sub-loops of a kinematic chain do not exist, therefore the existence of a sub-loop is verified first by the following set of rules

(a) For loop (1-2) to exist, there should be at least one common joint between loop-1 and loop-2. For example, in loop-joint matrix of figure 1a, loop (1-2) and loop (2-3) exists because joint (9-10) is common in loop-1 and loop-2 and joints (1-10), (1-4) and (1-9) are common in loop-2 and loop-3. But there is no common joint between loop-1 and loop-3; hence loop (1-3) does not exist. For loop (1-2-3) to exist, at least two loops from loop (1-2), loop (1-3) and loop (2-3) should exist. Similarly, for loop (1-2-3-4) to exist, at least two loops from loop (1-2-3), loop (1-2-4) and loop (2-3-4) should exist. 
(b) For any sub-loop (1-2-3-...-n) if (a) is satisfied and if any closed loop is completely surrounded by this combination of sub-loop, the loop will not exist e.g., for chain number ' 7 ' of 9 link, $M=2$, kinematic chains of Rao (2004), the sub-loop formed by the combination of loops $(1,3,2,6,8,7,5)$ and $(1,5$, $9,6,2,4)$ will not exist even though the joints (2-6) and (1-5) are common in these loops as the closed loop $(5,7,8,6,9)$ will be completely surrounded for this combination of loops.

Step 4: If a sub-loop exists, then the row of sub-loop of loop-joint matrix is filled by exclusive OR operations of respective independent loops (i.e., for combination of two loops, $0+0=0,0+1=1$ and $1+1=0$ ). When two independent loops are combined to form the sub-loop, the common joints between independent loops will not be there in the sub-loop and the exclusive OR operation will remove those common joints (as $1+1=0$ ) and those joints which are not common will remain in the sub-loop. For example; the sub-loop (1-2) of figure $1 \mathrm{a}$ is $(5,6,7,8,9,4,1,10)$ and it does not contain joint $(9,10)$ which is a common joint of independent loops 1 and 2. Similarly, if three independent loops are involved, this operation is performed for all the three loops for filling the corresponding row. All the sub-loops are thus determined and filled in loop-joint matrix.

Step 5: Loop size of a loop is calculated by summing the corresponding row values of loop and loop participation of joint (LPOJ) is found out by summing column values of corresponding joint. Total loop size (TLS) of kinematic chain is calculated by summing all the loop sizes.

Step 6: As each joint will participate in different combination of loops, the summation of loop sizes in which the joint is participating is called loop value of joint (LVOJ) and the sum of LVOJ value for all the joints is called chain loop value (CLV). The chain loop value can also be calculated by summing up the squared values of each loop size.

Step 7: The LPOJFS of kinematic chain is prepared by LPOJ values of joints in which At one's place: The number of joints which are not participating in any of the loops i.e., joints having $\mathrm{LPOJ}=0$.

At tenth place: The number of joints which are participating in only one loop i.e., joints having $\mathrm{LPOJ}=1$.

At hundredth place: The number of joints which are participating in two loops i.e., joints having $\mathrm{LPOJ}=2$ and so on.

Step 8: The LSFS of kinematic chain is prepared by all independent loops and sub-loops in which

At one's place: The number of loops having loop size $=4$.

At tenth place: The number of loops having loop size $=5$.

At hundredth place: The number of loops having loop size $=6$ and so on.

Step 9: Adjacent links (AL) and degree of links (DL) i.e., number of links connected to each link is found for each link. The link value (LV) of each link is defined as the sum of LVOJ values of joints to which it is connected e.g., link ' 1 ' of kinematic chain of figure 1a is connected with joints (1-4) and (1-10) having a LVOJ values of 18 and 18 , respectively (from figure 4 ). Therefore, the link value of link ' 1 ' is $18+18=36$. 


\begin{tabular}{|c|c|c|c|c|c|c|c|c|c|c|c|c|c|c|c|}
\hline \multirow[b]{2}{*}{ Loops/Joints } & \multirow[b]{2}{*}{5,6} & \multirow[b]{2}{*}{6,7} & \multirow[b]{2}{*}{7,8} & \multicolumn{7}{|c|}{ Loop Joint Matrix } & \multirow[b]{2}{*}{2,3} & \multirow[b]{2}{*}{2,10} & \multirow[b]{2}{*}{ LS } & & \\
\hline & & & & 8,9 & 9,10 & 5,10 & 1,4 & 4,9 & 1,10 & 3,9 & & & & & \\
\hline Loop-1 & 1 & 1 & 1 & 1 & 1 & 1 & 0 & 0 & 0 & 0 & 0 & 0 & 6 & & \\
\hline Loop-2 & 0 & 0 & 0 & 0 & 1 & 0 & 1 & 1 & 1 & 0 & 0 & 0 & 4 & & \\
\hline Loop-3 & 0 & 0 & 0 & 0 & 0 & 0 & 1 & 1 & 1 & 1 & 1 & 1 & 6 & & \\
\hline Loop (1-2) & 1 & 1 & 1 & 1 & 0 & 1 & 1 & 1 & 1 & 0 & 0 & 0 & 8 & & \\
\hline Loop (1-3) & 0 & 0 & 0 & 0 & 0 & 0 & 0 & 0 & 0 & 0 & 0 & 0 & 0 & & \\
\hline Loop (2-3) & 0 & 0 & 0 & 0 & 1 & 0 & 0 & 0 & 0 & 1 & 1 & 1 & 4 & & \\
\hline Loop $(1-2-3)$ & 1 & 1 & 1 & 1 & 0 & 1 & 0 & 0 & 0 & 1 & 1 & 1 & 8 & & \\
\hline LPO」 & 3 & 3 & 3 & 3 & 3 & 3 & 3 & 3 & 3 & 3 & 3 & 3 & 36 & TLS & \\
\hline LVO」 & 22 & 22 & 22 & 22 & 14 & 22 & 18 & 18 & 18 & 18 & 18 & 18 & 232 & CLV & \\
\hline LPOJFS & & & & & & & & & & & & & & & LSFS \\
\hline$[0,0,0,0,12,0,0,0]$ & & & & & & & & & & & & & & & {$[0,0,2,0,2,0,2]$} \\
\hline CS & \multicolumn{15}{|c|}{$\begin{array}{c}(36,232[0,0,2,0,2,0,2][4-72-188-520-1388,4-72-188-520-1388,2-44-88-204-480,2-44-88-204-480,2-44-116- \\
276-724,2-44-116-276-724,2-36-108-296-816,2-36-108-296-816,2-36-108-296-816,2-36-108-296-816])\end{array}$} \\
\hline & & & & & & & & & & & & & & & \\
\hline Link & AL & $\mathrm{DL}$ & $\mathrm{LV}$ & ALV 1 & ALV 2 & ALV 3 & LIS & & & & & & & & \\
\hline 1 & 4,10 & 2 & 36 & 108 & 296 & 816 & $2-36-108-296-816$ & & & & & & & & \\
\hline 2 & 3,10 & 2 & 36 & 108 & 296 & 816 & $2-36-108-296-816$ & & & & & & & & \\
\hline 3 & 9,2 & 2 & 36 & 108 & 296 & 816 & $2-36-108-296-816$ & & & & & & & & \\
\hline 4 & 1,9 & 2 & 36 & 108 & 296 & 816 & $2-36-108-296-816$ & & & & & & & & \\
\hline 5 & 6,10 & 2 & 44 & 116 & 276 & 724 & $2-44-116-276-724$ & & & & & & & & \\
\hline 6 & 5,7 & 2 & 44 & 88 & 204 & 480 & $2-44-88-204-480$ & & & & & & & & \\
\hline 7 & 6,8 & 2 & 44 & 88 & 204 & 480 & $2-44-88-204-480$ & & & & & & & & \\
\hline 8 & 7,9 & 2 & 44 & 116 & 276 & 724 & $2-44-116-276-724$ & & & & & & & & \\
\hline 9 & $8,10,4,3$ & 4 & 72 & 188 & 520 & 1388 & 4-72-188-520-1388 & & & & & & & & \\
\hline \multirow[t]{2}{*}{10} & $9,5,1,2$ & 4 & 72 & 188 & 520 & 1388 & $4-72-188-520-1388$ & & & & & & & & \\
\hline & & & & & & & \begin{tabular}{|c|}
$\mathrm{DM}=4$ \\
\end{tabular} & & & & & & & & \\
\hline
\end{tabular}

Figure 4. Loop-joint matrix for kinematic chain of figure 1a.

The link value of two links will be same if the summation of loop sizes in which they are participating is same.

Step 10: In literature, the adjacency of links is invariably used to determine the distinct links of kinematic chain. Rao \& Raju (2000) in their loop based methodology used the first adjacency of link to determine distinct link of kinematic chain. It has been observed that first adjacency is not always sufficient to distinguish among the links of a kinematic chain e.g., in chain number 61 of Mruthyunjaya (1984c) the first adjacency of link 7 and 8 is same but second adjacency is different, therefore the links are distinct. The loop based methodology proposed by Rao \& Raju (2000) fails in such occasions. Hence there is a need to calculate higher order adjacencies for accurate and precise determination of distinct links of kinematic chain. The number of adjacencies required to distinguish among the links depends on the highest loop size of kinematic chain but highest loop size for a kinematic chain having same number of links and mobility will vary from kinematic chain to kinematic chain. Hence there is a need to generalize the number of adjacency to be checked to distinguish the links of kinematic chain. As the highest possible loop size of a kinematic chain having ' $n$ ' number of links is ' $n$ ', therefore a formula has been proposed for the degree of adjacency to be checked for determination of distinct links of a kinematic chain. The adjacency to be checked (ADJ)

$$
\begin{aligned}
& A D J=\frac{n}{2}-2(\text { when } \mathrm{n} \text { is even }) \\
& A D J=\frac{(n-1)}{2}-2(\text { when } \mathrm{n} \text { is odd }) .
\end{aligned}
$$


This formula has a fundamental basis, for $\mathrm{n}=4$ and 5 , the first adjacency is always sufficient to distinguish the links of a kinematic chain. This formula is applicable to kinematic chains having two or more independent loops. Hence for seven link kinematic chain the first adjacency is calculated, for 8 and 9 link kinematic chain, second adjacency is calculated and so on.

Now first adjacency link value (ALV1) of a link is defined as summation of link values of its adjacent links e.g. for kinematic chain of figure 1a and from figure 4, the adjacent links of link ' 1 ' are '4' and '10' and link values of these links are 36 and 72 , respectively. Hence the first adjacency link value of link ' 1 ' is $36+72=108$. Similarly second adjacency link value (ALV2) is defined as the summation of first adjacency link values of adjacent links of ' 1 '. This process is repeated for calculating the higher order adjacencies of each link.

Step 11: The LIS of each link is formed by concatenating (DL, LV, ALV1, ALV2........ALVn). LIS represents the order of connectivity of a link in kinematic chain.

Step 12: The CS of kinematic chain is formed by concatenating TLS, CLV, LSFS and LIS of each link in decreasing order. The chain string of a kinematic chain posses all its topological characteristics, namely all the loops and their sizes, degree of links, order of connectivity of links or joints and higher order adjacencies of all links.

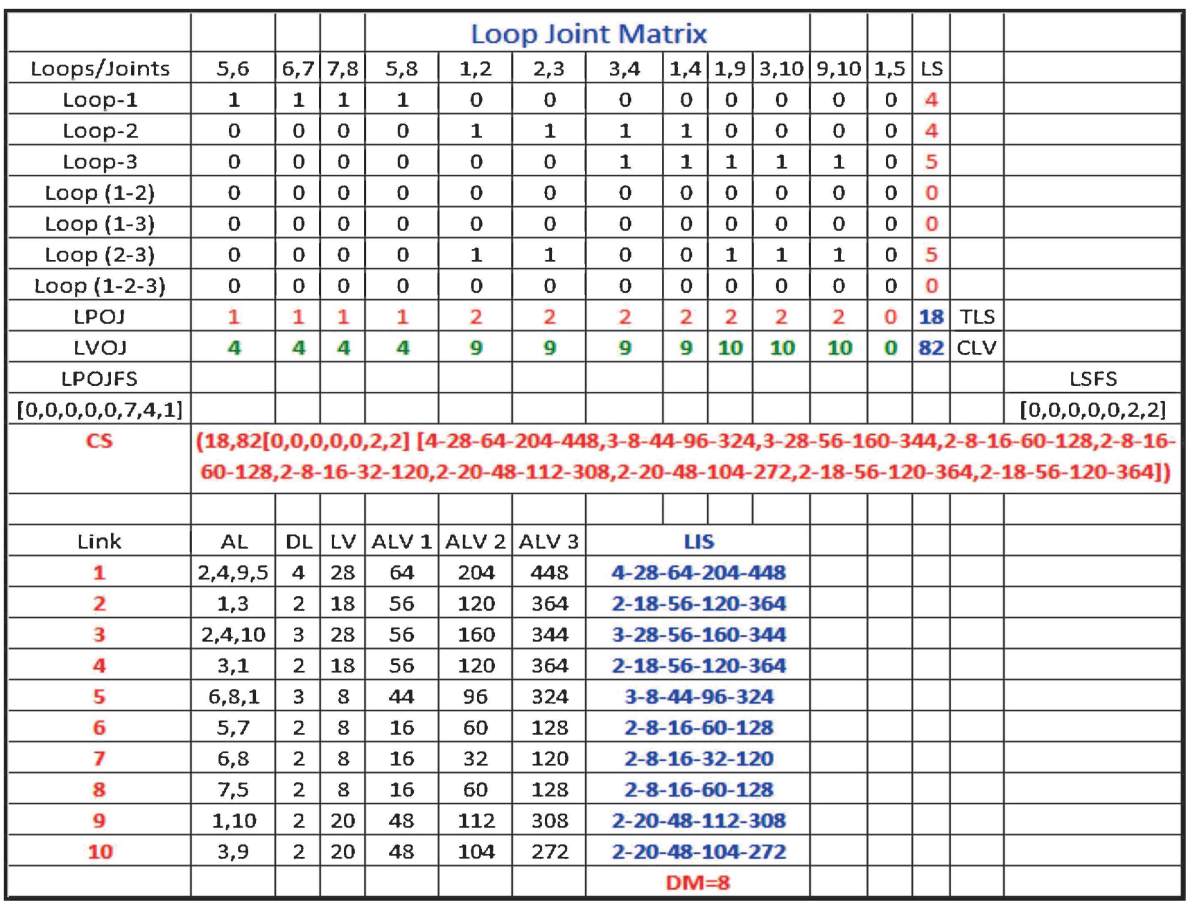

Figure 5. Loop-joint matrix for kinematic chain of figure $1 \mathrm{~b}$ showing joint fractionation at joint $(1,5)$. 


\section{Isomorphism identification}

The CS has potential to identify isomorphism among kinematic chains hence it is used as an invariant to detect the duplication or isomorphism among kinematic chains. If CS of two kinematic chains are same, then the chains are isomorphic otherwise non-isomorphic. To test the capability of chain string, two 15 link $(M=4)$ kinematic chains (Marin et al 2007) shown in figure 8 are tested for isomorphism.

The CS of kinematic chains of figures 8 is same and given as

$(208,2148$ [0,1,2,2,4,5,2,0,2,0,2,2] [3-376-886-2356-6290-16394, 3-376-752-2102-4698-13100, 3-374-878-2442-6188-17276, 3-374-862-2306-5630-15382, 3-304-886-2268-6226-15676, 3-304702-2236-5286-15324, 3-296-886-2442-6372-17264, 3-296-878-2252-6308-15828, 2-352-7501614-4408-10328, 2-216-592-1406-3834-9964, 2-216-520-1478-3674-10060, 2-206-678-15804678-11474, 2-206-670-1748-4748-12002, 2-200-680-1454-4338-9984, 2-200-672-1630-435411006]).

Hence, it can be concluded that these chains are isomorphic, Marin et al (2007) have given the same result for these two kinematic chains.

\begin{tabular}{|c|c|c|c|c|c|c|c|c|c|c|c|c|c|c|c|c|}
\hline \multirow[b]{2}{*}{ Loops/Joints } & \multirow[b]{2}{*}{6,9} & \multirow[b]{2}{*}{9,10} & \multirow[b]{2}{*}{10,11} & \multicolumn{7}{|c|}{ Loop Joint Matrix } & \multirow[b]{2}{*}{1,4} & \multirow[b]{2}{*}{4,5} & \multirow[b]{2}{*}{5,6} & \multirow[b]{2}{*}{ LS } & & \\
\hline & & & & 6,11 & 6,7 & 7,8 & 8,10 & \begin{tabular}{l|l|}
0 & 1,2 \\
\end{tabular} & 2,3 & 3,4 & & & & & & \\
\hline Loop-1 & 1 & 1 & 1 & 1 & 0 & 0 & 0 & 0 & 0 & \begin{tabular}{|l|}
0 \\
\end{tabular} & 0 & 0 & 0 & 4 & & \\
\hline Loop-2 & 1 & 1 & 0 & 0 & 1 & 1 & 1 & 0 & 0 & 0 & 0 & 0 & 0 & 5 & & \\
\hline Loop-3 & 0 & 0 & 0 & 0 & 0 & 0 & 0 & 1 & 1 & 1 & 1 & 0 & 0 & 4 & & \\
\hline Loop (1-2) & 0 & 0 & 1 & 1 & 1 & 1 & 1 & 0 & 0 & 0 & 0 & 0 & 0 & 5 & & \\
\hline Loop (1-3) & 0 & 0 & 0 & 0 & 0 & 0 & 0 & 0 & 0 & 0 & 0 & 0 & 0 & 0 & & \\
\hline Loop (2-3) & 0 & 0 & 0 & 0 & 0 & 0 & 0 & 0 & 0 & 0 & 0 & 0 & 0 & 0 & & \\
\hline Loop $(1-2-3)$ & 0 & 0 & 0 & 0 & 0 & 0 & 0 & 0 & 0 & 0 & 0 & 0 & 0 & 0 & & \\
\hline LPOJ & 2 & 2 & 2 & 2 & 2 & 2 & 2 & 1 & 1 & 1 & 1 & 0 & 0 & 18 & TLS & \\
\hline LVOJ & 9 & 9 & 9 & 9 & 10 & 10 & 10 & 4 & 4 & 4 & 4 & $\mathbf{0}$ & 0 & 82 & CLV & \\
\hline LPOJFS & & & & & & & & & & & & & & & & LSFS \\
\hline$[0,0,0,0,0,7,4,2]$ & & & & & & & & & & & & & & & & {$[0,0,0,0,0,0,2,2]$} \\
\hline CS & \multicolumn{16}{|c|}{$\begin{array}{c}(18,82[0,0,0,0,0,0,2,2][4-28-56-196-400,3-8-16-68-136,3-28-56-160-328,2-8-16-32-64,2-8-16-32-100,2 \\
8-16-32-100,2-20-48-104-300,2-20-48-104-264,2-18-56-112-356,2-18-56-112-356,2-0-36-72-264])\end{array}$} \\
\hline & & & & & & & & & & & & & & & & \\
\hline Link & AL & $\mathrm{DL}$ & LV & ALV 1 & ALV 2 & ALV 3 & \multicolumn{5}{|c|}{ US } & & & & & \\
\hline 1 & 2,4 & 2 & 8 & 16 & 32 & 100 & \multicolumn{5}{|c|}{$2-8-16-32-100$} & & & & & \\
\hline 2 & 1,3 & 2 & 8 & 16 & 32 & 64 & \multicolumn{5}{|c|}{$2-8-16-32-64$} & & & & & \\
\hline 3 & 2,4 & 2 & 8 & 16 & 32 & 100 & \multicolumn{5}{|c|}{$2-8-16-32-100$} & & & & & \\
\hline 4 & $3,1,5$ & 3 & 8 & 16 & 68 & 136 & \multicolumn{5}{|c|}{ 3-8-16-68-136 } & & & & & \\
\hline 5 & 4,6 & 2 & 0 & 36 & 72 & 264 & \multicolumn{5}{|c|}{$2-0-36-72-264$} & & & & & \\
\hline 6 & $9,11,7,5$ & 4 & 28 & 56 & 196 & 400 & \multicolumn{5}{|c|}{ 4-28-56-196-400 } & & & & & \\
\hline 7 & 6,8 & 2 & 20 & 48 & 104 & 300 & \multicolumn{5}{|c|}{$2-20-48-104-300$} & & & & & \\
\hline 8 & 7,10 & 2 & 20 & 48 & 104 & 264 & \multicolumn{5}{|c|}{$2-20-48-104-264$} & & & & & \\
\hline 9 & 6,10 & 2 & 18 & 56 & 112 & 356 & \multicolumn{5}{|c|}{ 2-18-56-112-356 } & & & & & \\
\hline 10 & $9,11,8$ & 3 & 28 & 56 & 160 & 328 & \multicolumn{5}{|c|}{$3-28-56-160-328$} & & & & & \\
\hline 11 & 10,6 & 2 & 18 & 56 & 112 & 356 & \multicolumn{5}{|c|}{ 2-18-56-112-356 } & & & & & \\
\hline & & & & & & & \multicolumn{5}{|c|}{$\mathrm{DM}=9$} & & & & & \\
\hline
\end{tabular}

Figure 6. Loop-joint matrix for kinematic chain of figure 2 showing a fractionated into body and serial type chain. 


\section{Identification of distinct mechanism (DM) from a given kinematic chain}

The loop-joint matrix has potential to identify DM derived from a kinematic chain. The LIS of links of kinematic chain are used to determine DM derived from a kinematic chain. If LIS of any two or more links are same, then the links are identical otherwise the links are distinct.

\begin{tabular}{|c|c|c|c|c|c|c|c|c|c|c|c|c|c|c|c|c|c|c|c|c|c|c|}
\hline \multirow[b]{2}{*}{ Loops/Joints } & \multirow[b]{2}{*}{1,2} & \multirow[b]{2}{*}{2,3} & \multirow[b]{2}{*}{3,4} & \multicolumn{10}{|c|}{ Loop Joint Matrix } & \multirow[b]{2}{*}{12,13} & \multirow[b]{2}{*}{10,13} & \multirow[b]{2}{*}{12,14} & \multirow[b]{2}{*}{14,15} & \multirow[b]{2}{*}{10,15} & & & & \\
\hline & & & & 1,4 & 5,6 & 6,7 & 7,8 & 5,8 & 8,99 & \begin{tabular}{l|l}
9,105 & 5 \\
\end{tabular} & \begin{tabular}{l|l}
5,10 & 1 \\
\end{tabular} & 10,11 & 11,12 & & & & & & 3,5 & LS & & \\
\hline Loop-1 & 1 & 1 & 1 & 1 & 0 & 0 & 0 & 0 & 0 & \begin{tabular}{l|l}
0 \\
\end{tabular} & \begin{tabular}{l|l}
0 \\
\end{tabular} & \begin{tabular}{|l|} 
\\
\end{tabular} & 0 & 0 & 0 & \begin{tabular}{|l|}
0 \\
\end{tabular} & 0 & 0 & 0 & 4 & & \\
\hline Loop-2 & 0 & 0 & 0 & 0 & 1 & 1 & 1 & 1 & 0 & 0 & 0 & 0 & 0 & 0 & 0 & 0 & 0 & 0 & 0 & 4 & & \\
\hline Loop-3 & 0 & 0 & 0 & 0 & 0 & 0 & 0 & 1 & 1 & 1 & 1 & 0 & 0 & 0 & 0 & 0 & 0 & 0 & 0 & 4 & & \\
\hline Loop-4 & 0 & 0 & 0 & 0 & 0 & 0 & 0 & 0 & 0 & 0 & 0 & 1 & 1 & 1 & 1 & 0 & 0 & 0 & 0 & 4 & & \\
\hline Loop-5 & 0 & 0 & 0 & 0 & 0 & 0 & 0 & 0 & 0 & 0 & 0 & 0 & 0 & 1 & 1 & 1 & 1 & 1 & 0 & 5 & & \\
\hline Loop (1-2) & 0 & 0 & 0 & 0 & 0 & 0 & 0 & 0 & 0 & 0 & 0 & 0 & 0 & 0 & 0 & 0 & 0 & 0 & 0 & 0 & & \\
\hline Loop (1-3) & 0 & 0 & 0 & 0 & 0 & 0 & 0 & 0 & 0 & 0 & 0 & 0 & 0 & 0 & 0 & 0 & 0 & 0 & 0 & 0 & & \\
\hline Loop (1-4) & 0 & 0 & 0 & 0 & 0 & 0 & 0 & 0 & 0 & 0 & 0 & 0 & 0 & 0 & 0 & 0 & 0 & 0 & 0 & 0 & & \\
\hline Loop (1-5) & 0 & 0 & 0 & 0 & 0 & 0 & 0 & 0 & 0 & 0 & 0 & 0 & 0 & 0 & 0 & 0 & 0 & 0 & 0 & 0 & & \\
\hline Loop $(2-3)$ & 0 & 0 & 0 & 0 & 1 & 1 & 1 & 0 & 1 & 1 & 1 & 0 & 0 & 0 & 0 & 0 & 0 & 0 & 0 & 6 & & \\
\hline Loop $(2-4)$ & 0 & 0 & 0 & 0 & 0 & 0 & 0 & 0 & 0 & 0 & 0 & 0 & 0 & 0 & 0 & 0 & 0 & 0 & 0 & 0 & & \\
\hline Loop (2-5) & 0 & 0 & 0 & 0 & 0 & 0 & 0 & 0 & 0 & 0 & 0 & 0 & 0 & 0 & 0 & 0 & 0 & 0 & 0 & 0 & & \\
\hline Loop (3-4) & 0 & 0 & 0 & 0 & 0 & 0 & 0 & 0 & 0 & 0 & 0 & 0 & 0 & 0 & 0 & 0 & 0 & 0 & 0 & 0 & & \\
\hline Loop (3-5) & 0 & 0 & 0 & 0 & 0 & 0 & 0 & 0 & 0 & 0 & 0 & 0 & 0 & 0 & 0 & 0 & 0 & 0 & 0 & 0 & & \\
\hline Loop (4-5) & 0 & 0 & 0 & 0 & 0 & 0 & 0 & 0 & 0 & 0 & 0 & 1 & 1 & 0 & 0 & 1 & 1 & 1 & 0 & 5 & & \\
\hline Loop $(1-2-3)$ & 0 & 0 & 0 & 0 & 0 & 0 & 0 & 0 & 0 & 0 & 0 & 0 & 0 & 0 & 0 & 0 & 0 & 0 & 0 & 0 & & \\
\hline Loop $(1-2-4)$ & 0 & 0 & 0 & 0 & 0 & 0 & 0 & 0 & 0 & 0 & 0 & 0 & 0 & 0 & 0 & 0 & 0 & 0 & 0 & 0 & & \\
\hline Loop (1-2-5) & 0 & 0 & 0 & 0 & 0 & 0 & 0 & 0 & 0 & 0 & 0 & 0 & 0 & 0 & 0 & 0 & 0 & 0 & 0 & 0 & & \\
\hline Loop $(1-3-4)$ & 0 & 0 & 0 & 0 & 0 & 0 & 0 & 0 & 0 & 0 & 0 & 0 & 0 & 0 & 0 & 0 & 0 & 0 & 0 & 0 & & \\
\hline Loop (1-3-5) & 0 & 0 & 0 & 0 & 0 & 0 & 0 & 0 & 0 & 0 & 0 & 0 & 0 & 0 & 0 & 0 & 0 & 0 & 0 & 0 & & \\
\hline Loop (1-4-5) & 0 & 0 & 0 & 0 & 0 & 0 & 0 & 0 & 0 & 0 & 0 & 0 & 0 & 0 & 0 & 0 & 0 & 0 & 0 & 0 & & \\
\hline Loop $(2-3-4)$ & 0 & 0 & 0 & 0 & 0 & 0 & 0 & 0 & 0 & 0 & 0 & 0 & 0 & 0 & 0 & 0 & 0 & 0 & 0 & 0 & & \\
\hline Loop $(2-3-5)$ & 0 & 0 & 0 & 0 & 0 & 0 & 0 & 0 & 0 & 0 & 0 & 0 & 0 & 0 & 0 & 0 & 0 & 0 & 0 & 0 & & \\
\hline Loop (2-4-5) & 0 & 0 & 0 & 0 & 0 & 0 & 0 & 0 & 0 & 0 & 0 & 0 & 0 & 0 & 0 & 0 & 0 & 0 & 0 & 0 & & \\
\hline Loop (3-4-5) & 0 & 0 & 0 & 0 & 0 & 0 & 0 & 0 & 0 & 0 & 0 & 0 & 0 & 0 & 0 & 0 & 0 & 0 & 0 & 0 & & \\
\hline Loop $(1-2-3-4)$ & 0 & 0 & 0 & 0 & 0 & 0 & 0 & 0 & 0 & 0 & 0 & 0 & 0 & 0 & 0 & 0 & 0 & 0 & 0 & 0 & & \\
\hline Loop $(1-2-3-5)$ & 0 & 0 & 0 & 0 & 0 & 0 & 0 & 0 & 0 & 0 & 0 & 0 & 0 & 0 & 0 & 0 & 0 & 0 & 0 & 0 & & \\
\hline Loop $(1-2-4-5)$ & 0 & 0 & 0 & 0 & 0 & 0 & 0 & 0 & 0 & 0 & 0 & 0 & 0 & 0 & 0 & 0 & 0 & 0 & 0 & 0 & & \\
\hline Loop $(1-3-4-5)$ & 0 & 0 & 0 & 0 & 0 & 0 & 0 & 0 & 0 & 0 & 0 & 0 & 0 & 0 & 0 & 0 & 0 & 0 & 0 & 0 & & \\
\hline Loop $(2-3-4-5)$ & 0 & 0 & 0 & 0 & 0 & 0 & 0 & 0 & 0 & 0 & 0 & 0 & 0 & 0 & 0 & 0 & 0 & 0 & 0 & 0 & & \\
\hline Loop (1-2-3-4-5) & 0 & 0 & 0 & 0 & 0 & 0 & 0 & 0 & 0 & 0 & 0 & 0 & 0 & 0 & 0 & 0 & 0 & 0 & 0 & 0 & & \\
\hline LPOJ & 1 & 1 & 1 & 1 & 2 & 2 & 2 & 2 & 2 & 2 & 2 & 2 & 2 & 2 & 2 & 2 & 2 & 2 & 0 & 32 & TLS & \\
\hline LVOJ & 4 & 4 & 4 & 4 & 10 & 10 & 10 & 8 & \begin{tabular}{|l|}
10 \\
\end{tabular} & \begin{tabular}{l|l}
10 & \\
\end{tabular} & 10 & 9 & 9 & 9 & 9 & 10 & 10 & 10 & 0 & 150 & CLV & \\
\hline LPOJFS & & & & & & & & & & & & & & & & & & & & & & LSFS \\
\hline$[0,0,0,0,0,0,0,0,0$, & $0,0,0,0,0,0,0,0$ & $0,0,0$ & $0,0,0$ & $0,0,0,0,0$ & $0,0,0,0$, & $0,14,4,1$ & & & & & & & & & & & & & & $0,0,0$, & $0,0,0, c$ & $0,0,1,2,4$ \\
\hline CS & \begin{tabular}{|l|}
$(32,150[0,0,0$ \\
$444-1552,2-8$
\end{tabular} & $\begin{array}{l}0,0,0 \\
8-16\end{array}$ & $\begin{array}{l}0,0,0 \\
-60\end{array}$ & $\begin{array}{r}0,0,0,1,2 \\
-168-504 \\
20\end{array}$ & $\begin{array}{l}2,4][5-1 \\
4,2-8-1 \\
-48-124\end{array}$ & $\begin{array}{l}48-104- \\
6-60-16 \\
4-352-96\end{array}$ & $\begin{array}{l}400-90 \\
8-504, \\
68,2-2\end{array}$ & $\begin{array}{l}8-32 \\
2-8-1 \\
0-48-1\end{array}$ & $\begin{array}{l}268,4-2 \\
16-32- \\
-116-3\end{array}$ & $\begin{array}{l}-28-10 \\
-120-3 \\
380-93\end{array}$ & $\begin{array}{l}04-264 \\
336,2- \\
32,2-1\end{array}$ & $\begin{array}{l}54-916- \\
2-20-76 \\
-18-76-\end{array}$ & $\begin{array}{l}2224,3 \\
5-172-6 \\
-160-60\end{array}$ & $\begin{array}{l}3-8-44- \\
628-146 \\
00-1352\end{array}$ & $\begin{array}{l}-136-38 \\
600,2-20 \\
2,2-18-\end{array}$ & $\begin{array}{l}84-1252, \\
0-68-152 \\
-76-160\end{array}$ & $\begin{array}{l}, 3-28-6 \\
2-524- \\
-600-1\end{array}$ & $\begin{array}{l}68-228 \\
1260,2 \\
352])\end{array}$ & $-552-$ & $\begin{array}{l}-1924 \\
48-15\end{array}$ & $\begin{array}{l}4,3-28 \\
52-380\end{array}$ & 3-56-200- \\
\hline Link & $A L$ & $\mathrm{DL}$ & LV & ALV 1 & ALV 2 & ALV 3 & ALV 4 & & & us & & & & & & & & & & & & \\
\hline 1 & 2,4 & 2 & 8 & 16 & 32 & 120 & 336 & & 2-8-16 & 6-32-1 & $120-33$ & & & & & & & & & & & \\
\hline 2 & 1,3 & 2 & 8 & 16 & 60 & 168 & 504 & & $2-8-16$ & 6-60-1 & $168-50$ & & & & & & & & & & & \\
\hline 3 & $2,4,5$ & 3 & 8 & 44 & 136 & 384 & 1252 & & $1-8-44$ & $-136-3$ & $384-12$ & 1252 & & & & & & & & & & \\
\hline 4 & 3,1 & 2 & 8 & 16 & 60 & 168 & 504 & & 2-8-16 & 6-60-1 & $168-50$ & & & & & & & & & & & \\
\hline 5 & $6,8,10,3$ & 4 & 28 & 104 & 264 & 916 & 2224 & & 28-104 & 4-264 & 1916-2 & 22224 & & & & & & & & & & \\
\hline 6 & 5,7 & 2 & 20 & 48 & 152 & 380 & 1296 & & $20-48$ & $3-152-3$ & $-380-1$ & 1296 & & & & & & & & & & \\
\hline 7 & 6,8 & 2 & 20 & 48 & 116 & 380 & 932 & & 2-20-48 & 8-116- & 5-380-9 & -932 & & & & & & & & & & \\
\hline 8 & $7,5,9$ & 3 & 28 & 68 & 228 & 552 & 1924 & & $28-68$ & $3-228-5$ & $-552-1$ & 1924 & & & & & & & & & & \\
\hline 9 & 8,10 & 2 & 20 & 76 & 172 & 628 & 1460 & & $-20-76-$ & $5-172-6$ & $-628-1$ & 1460 & & & & & & & & & & \\
\hline 10 & $9,5, \mathbf{1 1}, \mathbf{1 3 , 1 5}$ & 5 & 48 & 104 & 400 & 908 & 3268 & & 48-104 & $4-400-$ & p-908-3 & -3268 & & & & & & & & & & \\
\hline 11 & 10,12 & 2 & 18 & 76 & 160 & 600 & 1352 & & $-18-76$ - & $5-160-6$ & $-600-1$ & 1352 & & & & & & & & & & \\
\hline 12 & $11,13,14$ & 3 & 28 & 56 & 200 & 444 & 1552 & & $28-56-$ & $5-200-4$ & $-444-1$ & 1552 & & & & & & & & & & \\
\hline 13 & 12,10 & 2 & 18 & 76 & 160 & 600 & 1352 & & $-18-76$ & $5-160-6$ & $-600-1$ & 1352 & & & & & & & & & & \\
\hline 14 & 12,15 & 2 & 20 & 48 & 124 & 352 & 968 & & $20-48$ & 8-124- & $1-352-9$ & -968 & & & & & & & & & & \\
\hline 15 & 14,10 & 2 & 20 & 68 & 152 & 524 & 1260 & & $20-68$ & $3-152-5$ & $-524-1$ & 1260 & & & & & & & & & & \\
\hline & & & & & & & & & & $\mathrm{DM}=1$ & & & & & & & & & & & & \\
\hline
\end{tabular}

Figure 7. Loop-joint matrix for kinematic chain of figure 3 showing combination of body and joint fractionation. 


\section{Identification of type of mobility for kinematic chains having $M>1$}

In conceptual design of modern robots, the kinematic chains having $M>1$ are invariably used and these chains are required to be classified on the basis of type of mobility. The LPOJFS and LSFS have a potential to identify the type of mobility of kinematic chains having $M>1$ and is explained in the following sections. The kinematic chains having $M>1$ can possess following types of mobility.

\subsection{Total freedom mobility (TF)}

For a kinematic chain, the absence of any loop having loop size equal to 4 (for $M=2$ ), 4 and 5 (for $M=3$ ), 4, 5 and 6 (for $M=4$ ) and so on, then the kinematic chain has said to have total freedom mobility. If there is zero value at one's place of LSFS of kinematic chain, it indicates an absence of four bar loop. Similarly, zero value at tenth and hundredth place indicates the absence of five and six bar loop, respectively.

\subsection{Partial freedom mobility $(P F)$}

For a kinematic chain, the presence of any loop having loop size equal to 4 (for $M=2$ ), 4 and/or 5 (for $\mathrm{M}=3$ ), 4 and/or 5 and/or 6 (for $\mathrm{M}=4$ ) and so on then the kinematic chain has said to have partial freedom mobility. If there is any value other than zero at one's, tenth and hundredth place of LSFS of kinematic chain, it indicates the presence of four, five and six bar loop, respectively.

\subsection{Body or link fractionated freedom mobility $(B F F)$}

If there is zero at one's place and any value other than zero at tenth place of LPOJFS, then the kinematic chain possess body fractionated freedom mobility. Body fractionated kinematic chains having a mobility of ' $\mathrm{M}$ ' can be fractionated into two closed loop kinematic chains by cutting a specific link of it. The two fractionated kinematic chains have a combined mobility equal to ' $M$ ' e.g., the kinematic chain of figure 3 can be converted into two closed loop kinematic chains by cutting link 10. The value at tenth place of LPOJFS may be 4 (for kinematic chains having $M=2$ ), may be a multiple of 4 and/or 5 and their combination (for kinematic chains having $M=3$ ), may be a multiple of 4 and/or 5 and/or 6 and their combination (for kinematic chains having $M=4$ ) and so on. If there is 4 at tenth place of LPOJFS, it indicates that one of the fractionated chains
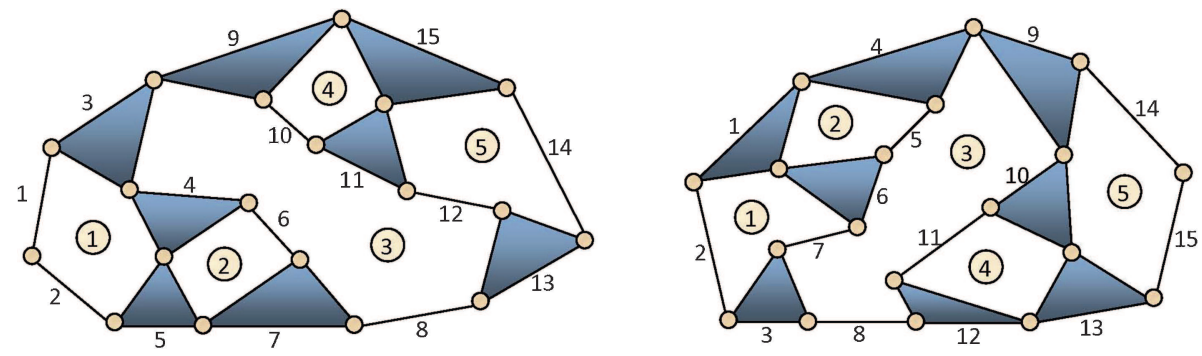

Figure 8. Two 15 link, $M=4$, isomorphic kinematic chains. 
has 4 links. In this manner the number of links of another kinematic chain can be calculated and mobility of both the fractionated kinematic chains can be evaluated.

\subsection{Joint or edge fractionated freedom mobility (EFF)}

If value at one's place of LPOJFS is 1, it indicates that the kinematic chain possesses joint fractionated freedom mobility. In joint fractionated kinematic chains, a joint divides the kinematic chain into two closed kinematic chains having a combined mobility of " $\mathrm{M}-1$ " (where ' $\mathrm{M}$ ' is the mobility of original kinematic chain). The kinematic chain of figure 1 (b) and its corresponding loop-joint matrix in figure 5 indicates that it can be fractionated into two closed kinematic chains by the joint (1-5) as its LPOJFS $[0,0,0,0,0,7,4,1]$.

\subsection{Fractionated into open chains}

The kinematic chains having $\mathrm{M}>=4$ possess more complex type of fractionation i.e., either the fractionation is a combination of body and joint fractionation or a combination of closed and serial kinematic chains. The kinematic chain of figure 2 and its corresponding loop-joint matrix shown in figure 6 indicates that it contains a combination of body and joint fractionation as the LPOJFS of kinematic chain is $[0,0,0,0,0,7,4,2]$. This kinematic chain can be fractionated into one closed loop and another serial chain by either of the joint (4-5) or (5-6). The LPOJFS of kinematic chain of figure 3 is $[0,0,0,0 \ldots, 0,14,4,1]$ (from figure 7). It indicates that this kinematic chain is a combination of body and joint fractionation.

\section{Conclusions}

(i). Although no mathematical proof has been presented, the authors believe that the proposed method is unique and may be applicable to planar kinematic chains of any size and mobility as it is utilizing all basic parameters of kinematic chain namely links, joints and all combination of loops.

(ii). The proposed method is capable of testing isomorphism among kinematic chains, finding distinct mechanism derived from kinematic chain and the type of mobility of multi degree of freedom kinematic chains from a single loop-joint matrix.

(iii). A computer program is developed for formulating the loop-joint matrix of a kinematic for which the inputs are independent loops, degree of mobility and additional joint (if any). The code of the program is written in $\mathrm{C \#}$, is available with the corresponding author. The authors have tested all the available $\mathrm{M}=1$ kinematic chains up to 12 links, $\mathrm{M}=2$ kinematic chains up to 11 links, $\mathrm{M}=3$ kinematic chains up to 12 links and $\mathrm{M}=4$ kinematic chains up to 11 links and found no counter example. The results of 9 links, $M=2$ (chain numbers are taken from Rao (2004)) and 10 links, $M=3$ kinematic chains (97 chains are taken from Mruthyunjaya (1984c) and $98^{\text {th }}$ chain is from Tischler et al (1995)) is given in appendix I and appendix II. The time taken to develop a loop-joint matrix for kinematic chains having 2 to 5 independent loops roughly varies from 4 to 8 seconds in Intel(R) Core(TM) Duo @ $1.66 \mathrm{GHz}$ computer having 512 MB RAM.

(iv). It is concluded that single adjacency is not enough to test the equivalence of links as proposed by authors in previous loop based methods in literature and a generalized formula is proposed for number of adjacency to be checked for finding the equivalence of links. 
(v). The invariants found by loop-joint matrix do not change by either redrawing or relabelling the kinematic chain.

\section{Appendix I}

\begin{tabular}{|c|c|c|c|c|c|}
\hline $\begin{array}{l}\text { Ch. } \\
\text { No. }\end{array}$ & Chain String (CS) & $D M$ & LPOJFS & LSFS & $\begin{array}{l}\text { Type of } \\
\text { Freedom }\end{array}$ \\
\hline KC1 & $\begin{array}{c}(44,284[0,1,2,2,2,0][3-78-156-464,3-78-156-464,3-76-180-488,3-76-180-488,2- \\
52-156-312,2-52-154-336,2-52-154-336,2-52-154-336,2-52-154-336])\end{array}$ & 4 & {$[0,0,0,11,0,0,0,0]$} & {$[0,1,2,2,2,0]$} & TF \\
\hline KC2 & $\begin{array}{c}(36,228[0,0,4,0,0,2][3-64-136-392,3-64-136-392,3-64-128-384,3-64-128-384,2- \\
56-128-256,2-36-128-264,2-36-128-264,2-36-128-264,2-36-128-264])\end{array}$ & 4 & {$[0,0,0,3,8,0,0,0]$} & {$[0,0,4,0,0,2]$} & $\mathrm{PF}$ \\
\hline KC3 & $\begin{array}{c}(44,288[1,0,1,3,2,2,0][3-78-184,-470,3-78-184-470,3-76-182-490,3-76-182-490,2- \\
56-134-318,2-56-134-318,2-52-154-366,2-52-154-366,2-52-152-364])\end{array}$ & 5 & {$[0,0,0,11,0,0,0,0]$} & {$[1,0,1,3,2,0]$} & TF \\
\hline KC4 & $\begin{array}{c}(44,288[0,2,0,4,0,1][3-80-160-448,3-76-208-492,3-76-180-516,3-76-180-516,2- \\
56-136-292,2-56-132-344,2-52-156-340,2-52-156-340,2-52-152-360])\end{array}$ & 7 & {$[0,0,0,11,0,0,0,0]$} & {$[0,2,0,4,0,1]$} & PF \\
\hline KC5 & $\begin{array}{c}(44,288[0,2,1,1,3,0][3-78-182-498,3-78-182-498,3-78-156-464,3-74-208-516,2- \\
56-134-316,2-56-134-316,2-52-156-338,2-52-156-338,2-52-152-364])\end{array}$ & 6 & {$[0,0,0,11,0,0,0,0]$} & {$[0,2,1,1,3,0]$} & TF \\
\hline KC6 & $\begin{array}{c}(44,288[0,1,3,1,1,1,[3-80-160-446,3-78-182-494,3-76-178-516,3-74-206-514,2- \\
56-136-294,2-56-134-318,2-52-156-338,2-52-154-366,2-52-154-360])\end{array}$ & 9 & {$[0,0,0,11,0,0,0,0]$} & {$[0,1,3,1,1,1]$} & PF \\
\hline KC7 & $\begin{array}{c}(35,211[0,0,2,2,1,1][3-62-132-354,3-62-132-354,3-60-130-372,3-60-130-372,2- \\
38-100-232,2-38-100-232,2-34-124-264,2-34-120-260,2-34-120-260])\end{array}$ & 5 & {$[0,0,0,2,9,0,0,0]$} & {$[0,0,2,2,1,1]$} & PF \\
\hline KC8 & $\begin{array}{c}(36,232[0,2,0,2,0,2][3-64-168-400,3-64-160-400,3-64-136-424,3-64-128-484,2- \\
56-128-288,2-40-104-272,2-40-104-264,2-36-128-264,2-36-128-264])\end{array}$ & 8 & {$[0,0,0,3,8,0,0,0]$} & {$[0,2,0,2,0,2]$} & $\mathrm{PF}$ \\
\hline KC9 & $\begin{array}{c}(44,292[1,1,0,2,3,0][3-78-184-500,3-78-184-500,3-76-210-526,3-76-210-526,2- \\
56-134-316,2-56-134-316,2-56-132-344,2-56-132-344,2-52-156-368])\end{array}$ & 5 & {$[0,0,0,11,0,0,0,0]$} & {$[1,1,0,2,3,0]$} & TF \\
\hline KC10 & $\begin{array}{c}(44,292[1,0,2,2,1,1][3-80-186-480,3-78-184-494,3-76-208-524,3-74-208-546,2- \\
56-136-320,2-56-136-318,2-56-134-320,2-56-132-344,2-52-152-392])\end{array}$ & 9 & {$[0,0,0,11,0,0,0,0]$} & {$[1,0,2,2,1,1]$} & PF \\
\hline KC11 & $\begin{array}{c}(44,292[0,2,2,0,2,1][3-80-184-508,3-78-180-526,3-78-180-526,3-72-236-544,2- \\
56-136-318,2-56-136-318,2-56-134-316,2-56-134-316,2-52-156-360])\end{array}$ & 6 & {$[0,0,0,11,0,0,0,0]$} & {$[0,2,2,0,2,1]$} & $\mathrm{PF}$ \\
\hline KC12 & $\begin{array}{c}(35,215[0,1,1,1,2,1][3-62-132-384,3-62-132-384,3-60-160-390,3-60-160-390,2- \\
38-98-258,2-38-98-258,2-38-100-232,2-38-100-232,2-34-124-264])\end{array}$ & 5 & {$[0,0,0,2,9,0,0,0]$} & {$[0,1,1,1,2,1]$} & $\mathrm{PF}$ \\
\hline КС13 & $\begin{array}{c}(44,296[1,1,1,1,2,2,1][3-80-186-506,3-78-210-530,3-76-182-516,3-74-210-546,2- \\
60-140-306,2-60-138-330,2-60-120-278,2-52-156-368,2-52-150-392])\end{array}$ & 9 & {$[0,0,0,11,0,0,0,0]$} & {$[1,1,1,1,2,1]$} & $\mathrm{PF}$ \\
\hline KC14 & $\begin{array}{l}(44,296[1,0,3,1,0,2][3-80-186-500,3-80-186-500,3-74-206-546,3-74-206-546,2- \\
60-140-306,2-60-140-306,2-60-120-280,2-52-154-392,2-52-154-392])\end{array}$ & 5 & {$[0,0,0,11,0,0,0,0]$} & {$[1,0,3,1,0,2]$} & $\mathrm{PF}$ \\
\hline KC15 & $\begin{array}{c}(44,296[0,3,0,2,0,2][3-80-184-532,3-80-184-532,3-76-176-548,3-72-236-544,2- \\
60-140-304,2-60-140-304,2-60-120-280,2-52-156-360,2-52-156-360])\end{array}$ & 6 & {$[0,0,0,11,0,0,0,0]$} & {$[0,3,0,2,0,2]$} & $\mathrm{PF}$ \\
\hline KC16 & $\begin{array}{c}(35,219[0,2,0,0,3,1][3-62-164-398,3-62-164-398,3-60-130-404,3-60-130-404,2- \\
42-84-208,2-42-104-248,2-42-104-248,2-34-120-260,2-34-120-260])\end{array}$ & 5 & {$[0,0,0,2,9,0,0,0]$} & {$[0,2,0,0,3,1]$} & $\mathrm{PF}$ \\
\hline KC17 & $\begin{array}{c}(36,236[1,0,2,0,1,2][3-64-168-432,3-64-168-432,3-64-160-400,3-64-160-400,2- \\
56-128-320,2-40-104-272,2-40-104-272,2-40-104-264,2-40-104-264])\end{array}$ & 5 & {$[0,0,0,3,8,0,0,0]$} & {$[1,0,2,0,1,2]$} & $\mathrm{PF}$ \\
\hline KC18 & $\begin{array}{c}(44,300[2,0,0,2,2,1][3-78-212-562,3-78-212-562,3-76-212-556,3-76-212-556,2- \\
60-138-332,2-60-138-332,2-60-120-276,2-56-132-344,2-56-132-344])\end{array}$ & 5 & {$[0,0,0,11,0,0,0,0]$} & {$[2,0,0,2,2,1]$} & $\mathrm{PF}$ \\
\hline KC19 & $\begin{array}{c}(35,223[1,0,1,1,1,2][3-62-164-428,3-62-164-428,3-60-160-422,3-60-160-422,2- \\
42-84-208,2-42-104-248,2-42-104-248,2-38-98-258,2-38-98-258])\end{array}$ & 5 & {$[0,0,0,2,9,0,0,0]$} & {$[1,0,1,1,1,2]$} & PF \\
\hline KC2O & $\begin{array}{c}(35,211[0,0,2,2,1,1][4-70-140-500,3-62-124-354,3-60-120-382,2-52-122-244,2- \\
38-108-240,2-38-100-232,2-34-132-264,2-34-130-260,2-34-130-260])\end{array}$ & 8 & {$[0,0,0,2,9,0,0,0]$} & {$[0,0,2,2,1,1]$} & $\mathrm{PF}$ \\
\hline KC21 & $\begin{array}{c}(36,228[0,0,4,0,0,2][4-72-144-544,3-64-128-392,3-64-128-392,2-56-120-248,2- \\
56-120-248,2-36-136-272,2-36-136-272,2-36-136-272,2-36-136-272])\end{array}$ & 4 & {$[0,0,0,3,8,0,0,0]$} & {$[0,0,4,0,0,2]$} & $\mathrm{PF}$ \\
\hline KC22 & $\begin{array}{c}(34,196[0,0,0,5,0,1][4-68-136-456,3-60-128-316,3-56-124-376,2-36-96-232,2-36- \\
96-232,2-36-104-232,2-36-104-232,2-32-124-260,2-32-124-260])\end{array}$ & 6 & {$[0,0,0,1,10,0,0,0]$} & {$[0,0,0,5,0,1]$} & $\mathrm{PF}$ \\
\hline KC23 & 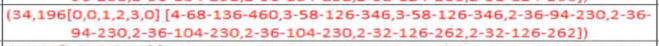 & 5 & {$[0,0,0,1,10,0,0,0]$} & {$[0,0,1,2,3,0]$} & TF \\
\hline KC24 & \begin{tabular}{|l}
$(18,82[0,0,0,0,2,2][4-28-64-192,3-28-64-176,3-28-56-168,2-8-36-80,2-8-36-80,2-$ \\
$8-16-72,2-20-56-120,2-18-56-120,2-18-56-120])$
\end{tabular} & 7 & {$[0,0,0,0,0,7,4,0]$} & {$[0,0,0,0,2,2]$} & BFF \\
\hline KC25 & $\begin{array}{c}(34,200[0,0,2,1,2,1][4-68-136-484,3-60-128-352,3-56-124-376,2-40-80-208,2-40- \\
108-216,2-40-100-208,2-32-128-264,2-32-124-260,2-32-124-260])\end{array}$ & 8 & {$[0,0,0,1,10,0,0,0]$} & {$[0,0,2,1,2,1]$} & PF \\
\hline KC26 & $\begin{array}{c}(35,215[0,1,1,1,2,1][4-70-170-508,3-62-124-354,3-60-160-390,2-52-122-284,2- \\
38-98-268,2-38-108-270,2-38-108-268,2-38-100-232,2-34-132-294])\end{array}$ & 9 & {$[0,0,0,2,9,0,0,0]$} & {$[0,1,1,1,2,1]$} & $\mathrm{PF}$ \\
\hline KC27 & $\begin{array}{c}(36,232[0,2,0,2,0,2][4-72-176-552,3-64-168-400,3-64-128-392,2-56-120-288,2- \\
56-120-248,2-40-112-280,2-40-104-280,2-36-136-304,2-36-136-304])\end{array}$ & 8 & {$[0,0,0,3,8,0,0,0]$} & {$[0,2,0,2,0,2]$} & $\mathrm{PF}$ \\
\hline KC28 & \begin{tabular}{|}
$(18,84[0,0,0,1,0,3][4-28-64-204,3-28-76-180,3-28-68-180,2-8-36-80,2-8-36-80,2-$ \\
$8-16-72,2-20-56-132,2-20-48-124,2-20-48-116])$
\end{tabular} & 8 & {$[0,0,0,0,0,7,4,0]$} & {$[0,0,0,1,0,3]$} & BFF \\
\hline KC29 & $\begin{array}{c}(35,219[0,2,0,0,3,1][4-70-172-536,3-62-164-398,3-60-120-382,2-52-122-284,2- \\
42-84-216,2-42-112-256,2-42-104-248,2-34-130-292,2-34-130-292])\end{array}$ & 8 & {$[0,0,0,2,9,0,0,0]$} & {$[0,2,0,0,3,1]$} & $\mathrm{PF}$ \\
\hline кС3о & $\begin{array}{c}(34,204[0,1,1,0,3,1][4-68-166-504,3-58-166-390,3-58-126-386,2-40-98-246,2-40- \\
80-206,2-40-108-246,2-36-94-230,2-36-104-260,2-32-126-292])\end{array}$ & 9 & {$[0,0,0,1,10,0,0,0]$} & {$[0,1,1,0,3,1]$} & $\mathrm{PF}$ \\
\hline KC31 & $\begin{array}{c}(18,82[0,0,0,0,2,2][4-26-72-196,3-28-64-176,3-28-64-176,2-8-34-88,2-8-34-88,2- \\
8-16-68,2-20-48-112,2-20-48-112,2-18-56-128])\end{array}$ & 6 & {$[0,0,0,0,0,7,4,0]$} & {$[0,0,0,0,2,2]$} & $\mathrm{BFF}$ \\
\hline кC32 & $\begin{array}{c}(34,200[0,0,2,1,2,1][4-68-164-476,3-60-128-356,3-56-164-384,2-36-96-232,2-36- \\
96-232,2-36-92-268,2-36-104-260,2-36-104-260,2-36-104-256])\end{array}$ & 7 & {$[0,0,0,1,10,0,0,0]$} & {$[0,0,2,1,2,1]$} & $\mathrm{PF}$ \\
\hline ксз3 & $\begin{array}{c}(18,82[0,0,0,0,2,2][5-36-72-272,3-28-56-176,2-8-44-88,2-8-44-88,2-8-16-88,2-20 \\
56-120,2-20-48-112,2-18-64-128,2-18-64-128])\end{array}$ & 7 & {$[0,0,0,0,0,7,4,0]$} & {$[0,0,0,0,2,2]$} & $\mathrm{BFF}$ \\
\hline кC34 & $\begin{array}{c}(34,204[0,1,0,3,0,2][4-68-164-504,3-60-128-392,3-56-164-384,2-40-80-208,2-40- \\
108-244,2-40-100-208,2-36-92-268,2-36-104-256,2-32-128-292])\end{array}$ & 9 & {$[0,0,0,1,10,0,0,0]$} & {$[0,1,0,3,0,2]$} & $\mathrm{PF}$ \\
\hline KC35 & $\begin{array}{c}(36,236[1,0,2,0,1,2][4-72-208-560,3-64-168-432,3-64-168-432,2-56-120-288,2- \\
56-120-288,2-40-112-312,2-40-112-312,2-40-104-280,2-40-104-280])\end{array}$ & 5 & {$[0,0,0,3,8,0,0,0]$} & {$[1,0,2,0,1,2]$} & PF \\
\hline кС36 & $\begin{array}{c}(44,304[2,0,1,1,1,2][4-106-274-760,3-80-218-572,3-78-214-566,2-60-166-394,2- \\
60-140-338,2-60-120-306,2-56-162-408,2-56-134-376,2-52-158-432])\end{array}$ & 9 & {$[0,0,0,11,0,0,0,0]$} & {$[2,0,1,1,1,2]$} & $\mathrm{PF}$ \\
\hline КС37 & $\begin{array}{c}(33,183[0,0,0,3,3,0][4-66-132-432,4-66-132-432,2-34-100-232,2-34-100-232,2- \\
34-100-232,2-34-100-232,2-34-100-232,2-34-100-232,2-30-132-264])\end{array}$ & 3 & {$[0,0,0,0,11,0,0,0]$} & {$[0,0,0,3,3,0]$} & TF \\
\hline кC38 & $\begin{array}{c}(33,187[0,0,1,2,2,2,1][4-66-132-468,4-66-132-468,2-38-76-208,2-38-104-208,2-38- \\
104-208,2-34-100-232,2-34-100-232,2-30-132-264,2-30-132-264]]\end{array}$ & 5 & {$[0,0,0,0,11,0,0,0]$} & {$[0,0,1,2,2,1]$} & PF \\
\hline кс39 & $\begin{array}{c}(33,191[0,0,2,1,1,2][4-66-172-476,4-66-172-476,2-38-76-208,2-38-104-248,2-38- \\
104-248,2-34-100-272,2-34-100-272,2-34-100-272,2-34-100-272])\end{array}$ & 4 & {$[0,0,0,0,11,0,0,0]$} & {$[0,0,2,1,1,2]$} & $\mathrm{PF}$ \\
\hline \multirow[t]{2}{*}{ KC4O } & \begin{tabular}{|c}
$(18,84[0,0,0,1,0,3][5-36-84-276,3-28-76-180,2-8-44-100,2-8-44-100,2-8-16-88,2-$ \\
$20-56-132,2-20-56-132,2-20-48-132,2-20-48-132])$
\end{tabular} & 6 & {$[0,0,0,0,0,7,4,0]$} & {$[0,0,0,1,0,3]$} & BFF \\
\hline & 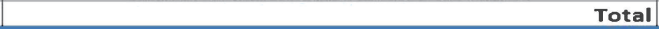 & 254 & & & \\
\hline
\end{tabular}

Figure 9. Nine link. $M=2$. Kinematic chains. 


\section{Appendix II}

\begin{tabular}{|c|c|c|c|c|c|}
\hline $\begin{array}{l}\text { Ch. } \\
\text { No. }\end{array}$ & Chain String (CS) & DM & LPOJFS & LSFS & $\begin{array}{l}\text { Type of } \\
\text { Freedom }\end{array}$ \\
\hline KC1 & 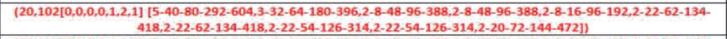 & 7 & {$[0,0,0,0,0,8,4,0]$} & {$[0,0,0,0,1,2,1]$} & BFF \\
\hline $\mathrm{KC2}$ & 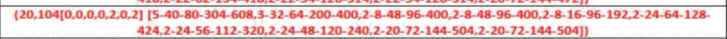 & 8 & {$[0,0,0,0,0,8,4,0]$} & {$[0,0,0,0,2,0,2]$} & BFF \\
\hline KC3 & 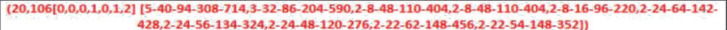 & 9 & {$[0,0,0,0,0,8,4,0]$} & {$[0,0,0,1,0,1,2]$} & $\mathrm{BFF}$ \\
\hline KC4 & 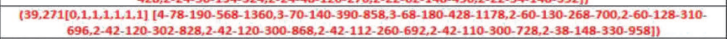 & 10 & {$[0,0,0,3,9,0,0,0]$} & {$[0,1,1,1,1,1,1]$} & $\mathrm{PF}$ \\
\hline KC5 & 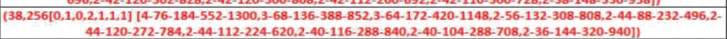 & 10 & {$[0,0,0,2,10,0,0,0]$} & {$[0,1,0,2,1,1,1]$} & $\mathrm{PF}$ \\
\hline KC6 & 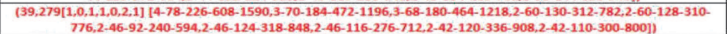 & 10 & {$[0,0,0,3,9,0,0,0]$} & {$[1,0,1,1,0,2,1]$} & $\mathrm{PF}$ \\
\hline KC7 & 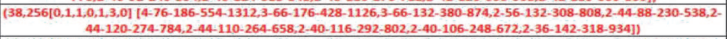 & 10 & {$[0,0,0,2,10,0,0,0]$} & {$[0,1,1,0,1,3,0]$} & $\mathrm{PF}$ \\
\hline KC8 & 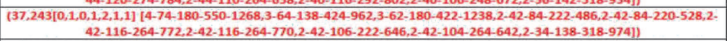 & 10 & {$[0,0,0,1,11,0,0,0]$} & {$[0,1,0,1,2,1,1]$} & $\mathrm{PF}$ \\
\hline KC9 & 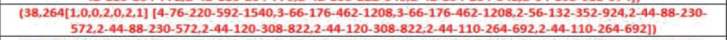 & 6 & {$[0,0,0,2,10,0,0,0]$} & {$[1,0,0,2,0,2,1]$} & $\mathrm{PF}$ \\
\hline KC10 & 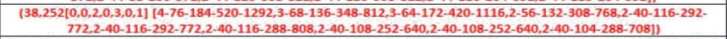 & 8 & {$[0,0,0,2,10,0,0,0]$} & {$[0,0,2,0,3,0,1]$} & $\mathrm{PF}$ \\
\hline KC11 & 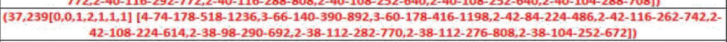 & 10 & {$[0,0,0,1,11,0,0,0]$} & {$[0,0,1,2,1,1,1]$} & $\mathrm{PF}$ \\
\hline KC12 & 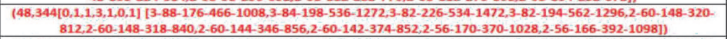 & 10 & {$[0,0,0,12,0,0,0,0]$} & {$[0,1,1,3,1,0,1]$} & $\mathrm{PF}$ \\
\hline KC13 & 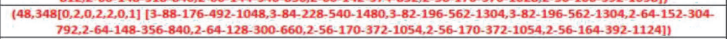 & 8 & {$[0,0,0,12,0,0,0,0]$} & {$[0,2,0,2,2,0,1]$} & $\mathrm{PF}$ \\
\hline KC14 & 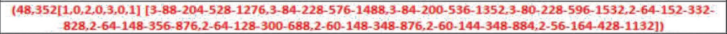 & 10 & {$[0,0,0,12,0,0,0,0]$} & {$[1,0,2,0,3,0,1]$} & $\mathrm{PF}$ \\
\hline KC15 & 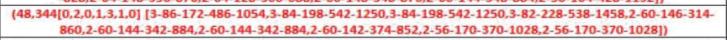 & 7 & {$[0,0,0,12,0,0,0,0]$} & {$[0,2,0,1,3,1,0]$} & $\mathrm{PF}$ \\
\hline KC16 & 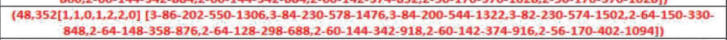 & 10 & {$[0,0,0,12,0,0,0,0]$} & {$[1,1,0,1,2,2,0]$} & $\mathrm{PF}$ \\
\hline KC17 & 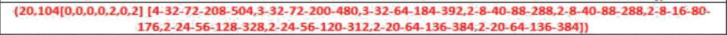 & 8 & {$[0,0,0,0,0,8,4,0]$} & {$[0,0,0,0,2,0,2]$} & BFF \\
\hline KC18 & 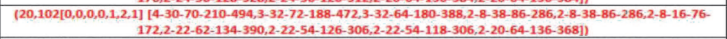 & 9 & {$[0,0,0,0,0,8,4,0]$} & {$[0,0,0,0,1,2,1]$} & BFF \\
\hline KC19 & 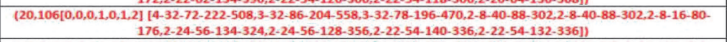 & 9 & {$[0,0,0,0,0,8,4,0]$} & {$[0,0,0,1,0,1,2]$} & BFF \\
\hline KC2O & 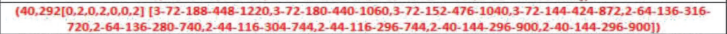 & 9 & {$[0,0,0,4,8,0,0,0]$} & {$[0,2,0,2,0,0,2]$} & $\mathrm{PF}$ \\
\hline KC21 & 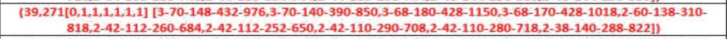 & 10 & {$[0,0,0,3,9,0,0,0]$} & {$[0,1,1,1,1,1,1]$} & $\mathrm{PF}$ \\
\hline $\mathrm{KC22}$ & 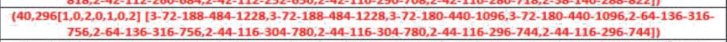 & 5 & {$[0,0,0,4,8,0,0,0]$} & {$[1,0,2,0,1,0,2]$} & $\mathrm{PF}$ \\
\hline KC23 & 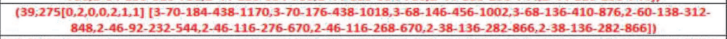 & 9 & {$[0,0,0,3,9,0,0,0]$} & {$[0,2,0,0,2,1,1]$} & $\mathrm{PF}$ \\
\hline $\mathrm{KC24}$ & 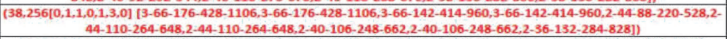 & 6 & {$[0,0,0,2,10,0,0,0]$} & {$[0,1,1,0,1,3,0]$} & $\mathrm{PF}$ \\
\hline $\mathrm{KC25}$ & 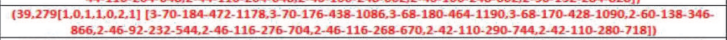 & 10 & {$[0,0,0,3,9,0,0,0]$} & {$[1,0,1,1,0,2,1]$} & $\mathrm{PF}$ \\
\hline KC26 & 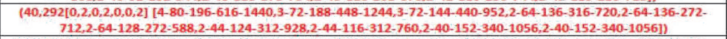 & 9 & {$[0,0,0,4,8,0,0,0]$} & {$[0,2,0,2,0,0,2]$} & $\mathrm{PF}$ \\
\hline KC27 & 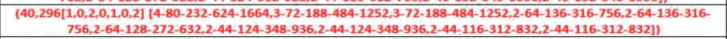 & 6 & {$[0,0,0,4,8,0,0,0]$} & {$[1,0,2,0,1,0,2]$} & PF \\
\hline KC28 & 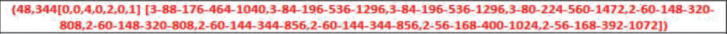 & 7 & {$[0,0,0,12,0,0,0,0]$} & {$[0,0,4,0,2,0,1]$} & $\mathrm{PF}$ \\
\hline KC29 & 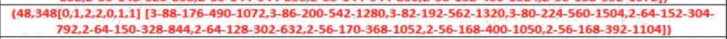 & 10 & {$[0,0,0,12,0,0,0,0]$} & {$[0,1,2,2,0,1,1]$} & PF \\
\hline Кс30 & 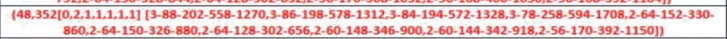 & 10 & {$[0,0,0,12,0,0,0,0]$} & {$[0,2,1,1,1,1,1]$} & $\mathrm{PF}$ \\
\hline KC31 & 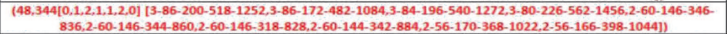 & 10 & {$[0,0,0,12,0,0,0,0]$} & {$[0,1,2,1,1,2,0]$} & $\mathrm{PF}$ \\
\hline KC32 & 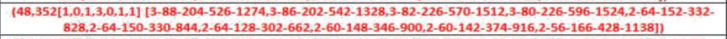 & 10 & {$[0,0,0,12,0,0,0,0]$} & {$[1,0,1,3,0,1,1]$} & $\mathrm{PF}$ \\
\hline кC33 & 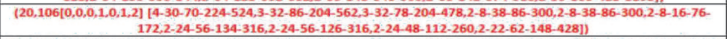 & 9 & {$[0,0,0,0,0,8,4,0]$} & {$[0,0,0,1,0,1,2]$} & BFF \\
\hline KC34 & \begin{tabular}{|l}
$(12,48[0,0,0,0,0,0,0,3]$ \\
{$[4-16-40-112-288,4-16-40-112-288,2-8-24-64-176,2-8-24-64-176,2-8-24-56-160,2-8-24-56-160,2-8$} \\
$24-56-160,2-8-24-56-160,2-8-16-48-112,2-8-16-48-112])$
\end{tabular} & 4 & {$[0,0,0,0,0,0,12,0]$} & {$[0,0,0,0,0,0,3]$} & BFF \\
\hline KC35 & 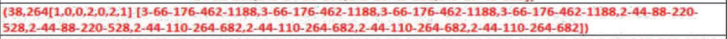 & 3 & {$[0,0,0,2,10,0,0,0]$} & {$[1,0,0,2,0,2,1]$} & $\mathrm{PF}$ \\
\hline KC36 & 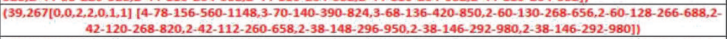 & 9 & {$[0,0,0,3,9,0,0,0]$} & {$[0,0,2,2,0,1,1]$} & PF \\
\hline KC37 & 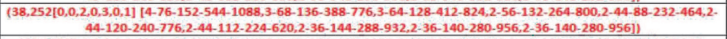 & 9 & {$[0,0,0,2,10,0,0,0]$} & {$[0,0,2,0,3,0,1]$} & PF \\
\hline KC38 & 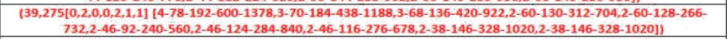 & 9 & {$[0,0,0,3,9,0,0,0]$} & {$[0,2,0,0,2,1,1]$} & $\mathrm{PF}$ \\
\hline Kс39 & 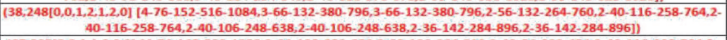 & 6 & {$[0,0,0,2,10,0,0,0]$} & {$[0,0,1,2,1,2,0]$} & $\mathrm{PF}$ \\
\hline KC40 & 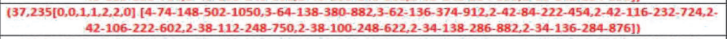 & 10 & {$[0,0,0,1,11,0,0,0]$} & {$[0,0,1,1,2,2,0]$} & PF \\
\hline KC41 & 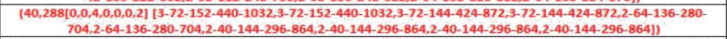 & 4 & {$[0,0,0,4,8,0,0,0]$} & {$[0,0,4,0,0,0,2]$} & PF \\
\hline KC42 & 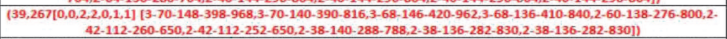 & 9 & {$[0,0,0,3,9,0,0,0]$} & {$[0,0,2,2,0,1,1]$} & PF \\
\hline KC43 & 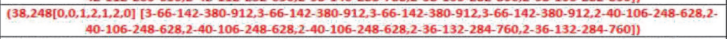 & 3 & {$[0,0,0,2,10,0,0,0]$} & {$[0,0,1,2,1,2,0]$} & $\mathrm{PF}$ \\
\hline KC44 & 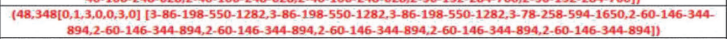 & 3 & {$[0,0,0,12,0,0,0,0]$} & {$[0,1,3,0,0,3,0]$} & $\mathrm{PF}$ \\
\hline KC45 & 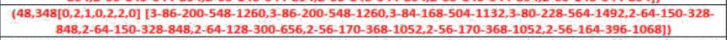 & 7 & {$[0,0,0,12,0,0,0,0]$} & {$[0,2,1,0,2,2,0]$} & $\mathrm{PF}$ \\
\hline KC46 & 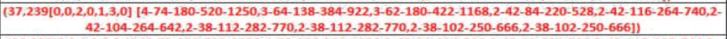 & 8 & {$[0,0,0,1,11,0,0,0]$} & {$[0,0,2,0,1,3,0]$} & PF \\
\hline KC47 & 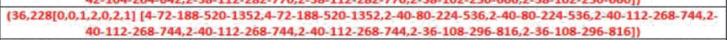 & 4 & {$[0,0,0,0,12,0,0,0]$} & {$[0,0,1,2,0,2,1]$} & $\mathrm{PF}$ \\
\hline KC48 & 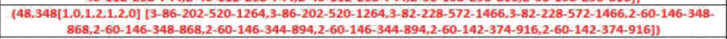 & 5 & {$[0,0,0,12,0,0,0,0]$} & {$[1,0,1,2,1,2,0]$} & $\mathrm{PF}$ \\
\hline KC49 & 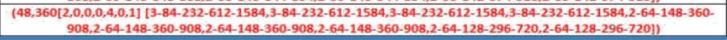 & 3 & {$[0,0,0,12,0,0,0,0]$} & {$[2,0,0,0,4,0,1]$} & $\mathrm{PF}$ \\
\hline
\end{tabular}

Figure 10. Ten link. $M=3$. Kinematic chains. 


\begin{tabular}{|c|c|c|c|c|c|}
\hline \multicolumn{6}{|l|}{ Contd... } \\
\hline $\begin{array}{l}\text { Ch. } \\
\text { No. }\end{array}$ & Chain String (CS) & $D M$ & LPOJFS & LSFS & $\begin{array}{l}\text { Type of } \\
\text { Freedom }\end{array}$ \\
\hline KC50 & $\begin{array}{c}(48,340[0,0,3,20.2 .0][3-86-172-482-1050,3-86-172-482-1050,3-82-194-530-1262,3-82-194-530-1262.2-60-146-318 \\
800,2-60-146-318-800,2-56-168-366-1012,2-56-168-366-1012,2-56-168-366-1012,2-56-168-366-1012])\end{array}$ & 4 & {$[0,0,0,12,0,0,0,0]$} & {$[0,0,3,2,0,2,0]$} & PF \\
\hline KC51 & $\begin{array}{c}\text { (48,340[0.1.1,2,2,1.0] [3-86-172-484-1024,3-84-198-508-1242,3-84-168-504-1070,3-82-196-532-1240,2-60-146-316- } \\
828,2-60-144-344-824,2-56-170-340-988,2-56-168-368-1016,2-56-168-366-1012,2-56-166-364-1036])\end{array}$ & 10 & {$[0,0,0,12,0,0,0,0]$} & {$[0,1,1,2,2,1,0]$} & PF \\
\hline $\mathrm{KC5} 2$ & 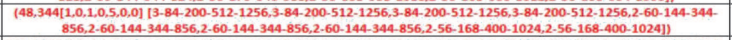 & 3 & {$[0,0,0,12,0,0,0,0]$} & {$[1,0,1,0,5,0,0]$} & TF \\
\hline KC53 & $\begin{array}{c}(38,248[0,0,0,4,1,0,1][4-76-152-512-1080,3-68-136-348-768,3-64-128-412-824,2-56-132-264-760,2-40-116-260-764,2- \\
40-116-260-764,2-40-108-252-608,2-40-108-252-608,2-36-140-280-924,2-36-140-280-924])\end{array}$ & 7 & {$[0,0,0,2,10,0,0,0]$} & {$[0,0,0,4,1,0,1]$} & PF \\
\hline KC54 & \begin{tabular}{|c|}
$(37,235[0,0,0,3,2,0,1][14-74-148-496-1048,3-66-140-346-884,3-60-134-408-910,2-42-84-224-456,2-42-116-232-720,2-$ \\
$42-108-224-570,2-38-112-252-748,2-38-104-252-598,2-34-134-282-904,2-34-134-282-904])$
\end{tabular} & 9 & {$[0,0,0,1,11,0,0,0]$} & {$[0,0,0,3,2,0,1]$} & PF \\
\hline KC55 & $\begin{array}{c}(37,231[0,0,0,2,2,1,0][4-74-148-472-1032,3-64-138-340-874,3-62-136-374-872,2-38-112-250-722,2-38-112-250-722,2- \\
38-112-248-720,2-38-102-250-590,2-38-102-250-590,2-38-100-248-622,2-34-136-284-846])\end{array}$ & 8 & {$[0,0,0,1,11,0,0,0]$} & {$[0,0,0,2,3,1,0]$} & PF \\
\hline KC56 & $\begin{array}{c}(36,220[0,0,0,2,2,2,0][4-72-144-472-1016,4-72-144-472-1016,2-40-80-224-448,2-40-112-224-696,2-40-112-224-696,2- \\
36-108-252-724,2-36-108-252-724,2-36-108-252-724,2-36-108-252-724,2-32-144-288-944])\end{array}$ & 5 & {$[0,0,0,0,12,0,0,0]$} & {$[0,0,0,2,2,2,0]$} & PF \\
\hline KC57 & \begin{tabular}{|c|}
$(48,348[1,0,1,2,1.2,0][3]-86-202-516-1264,3-86-202-516-1264,3-82-198-534-1312,3-82-198-534-1312.2-64-150-330-$ \\
$816,2-64-150-330-816,2-64-128-300-660,2-56-168-400-1050,2-56-168-400-1050,2-56-164-396-1068])$
\end{tabular} & 6 & {$[0,0,0,12,0,0,0,0]$} & {$[1,0,1,2,1,2,0]$} & PF \\
\hline KC58 & $\begin{array}{c}(48,344[1,0,0,3,2,1,0][3-86-202-490-1226,3-84-200-510-1254,3-84-200-510-1254,3-82-198-534-1286,2-60-146-346- \\
836,2-60-146-346-836,2-60-144-346-856,2-60-144-346-856,2-56-166-398-1044,2-56-166-398-1044])\end{array}$ & 6 & {$[0,0,0,12,0,0,0,0]$} & {$[1,0,0,3,2,1,0]$} & PF \\
\hline KC59 & $\begin{array}{c}(40,288[0,0,4,0,0,0,2][4-80-160-608-1216,3-72-144-440-880,3-72-1444-440-880,2-64-136-272-712,2-64-136-272-712,2- \\
64-128-272-544,2-40-152-304-1048,2-40-152-304-1048,2-40-152-304-1048,2-40-152-304-1048])\end{array}$ & 5 & {$[0,0,0,4,8,0,0,0]$} & {$[0,0,4,0,0,0,2]$} & PF \\
\hline KC60 & 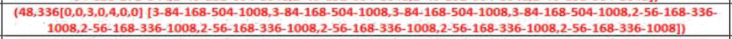 & 2 & {$[0,0,0,12,0,0,0,0]$} & {$[0,0,3,0,4,0,0]$} & TF \\
\hline KC61 & $\begin{array}{c}38,268[1,0,1,0,2,0,2][4-76-220-592-1564,3-68-180-468-1220,3-64-172-456-1232,2-56-132-352-924,2-48-96-220 \\
528,2-48-96-212-496,2-48-124-316-812,2-48-116-276-680,2-40-116-324-880,2-40-104-288-780])\end{array}$ & 10 & {$[0,0,0,2,10,0,0,0]$} & {$[1,0,1,0,2,0,2]$} & PF \\
\hline KC62 & \begin{tabular}{|c|}
$(37,247[0,1,0,2,1,0,2]$ \\
$46-120-270-76-178-550-1280,3-66-140-430-966,3-60-178-416-1270,2-46-92-212-474,2-46-92-204-444,2-2$ \\
\end{tabular} & 10 & {$[0,0,0,1,11,0,0,0]$} & {$[0,1,0,2,1,0,2]$} & PF \\
\hline KC63 & $\begin{array}{c}(38.264[0.2 .0 .0,1.2,1][4-76-188-584-1352,3-68-480-436-1168,3-64,-128-412-940,2-56-132-308-848,2-48-96-220-496,2- \\
48-96-212-496,2-48-124-284-804,2-48-116-276-648,2-36-140-316-996,2-36-140-316-96])\end{array}$ & 9 & {$[0,0,0,2,10,0,0,0]$} & {$[0,2,0,0,1,2,1]$} & PF \\
\hline KC64 & 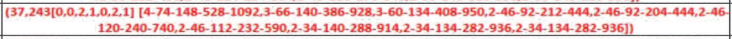 & 9 & {$[0,0,0,1,11,0,0,0]$} & {$[0,0,2,1,0,2,1]$} & $\mathrm{PF}$ \\
\hline KC65 & 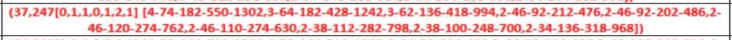 & 10 & {$[0,0,0,1,11,0,0,0]$} & {$[0,1,1,0,1,2,1]$} & PF \\
\hline KC66 & $\begin{array}{c}(36,228[0,0.1,2,0.2,1] \\
44-116-232-716,-12-36-108-252-764,2-36-108-252-764,2-32-144-288-1024,2-32-144-288-1024]]\end{array}$ & 5 & {$[0,0,0,0,12,0,0,0]$} & {$[0,0,1,2,0,2,1]$} & PF \\
\hline KC67 & 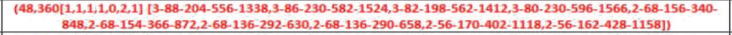 & 10 & {$[0,0,0,12,0,0,0,0]$} & {$[1,1,1,1,0,2,1]$} & PF \\
\hline KC68 & $\begin{array}{c}(48,360[0,3,0,1,1,0,2][3-88-202-584-1324,3-88-202-584-1324,3-282-190-598-1378,3-78-258-594-1766,2-68-156-338 \\
876,2-68-156-338-876,2-68-136-292-630,2-68-136-292-630,2-56-170-392-1182,2-56-170-392-1182])\end{array}$ & 6 & {$[0,0,0,12,0,0,0,0]$} & {$[0,3,0,1,1,0,2]$} & PF \\
\hline KC69 & $\begin{array}{c}\text { (48,360[1,0,3,0,1.0.2] [3-88-204-548-1364,3-88-204-548-1364,3-80-224-596-1572,3-80-224-596-1572,2-68-156-340- } \\
840,2-68-156-340-840,2-68-136-292-632,2-68-136-292-632,2-56-168-428-1144,2-56-168-428-1144])\end{array}$ & 5 & {$[0,0,0,12,0,0,0,0]$} & {$[1,0,3,0,1,0,2]$} & PF \\
\hline KC7O & $\begin{array}{c}(48,364[2,0.0,20.2,1][3-86-232-618-1580,3-86-232-618-1580,3-82-232-606-1610,3-82-232-606-1610.2-68-154-368- \\
908,2-68-154-368-908,2-68-136-290-658,2-68-136-290-658,2-60-142-374-980,2-60-142-374-980])\end{array}$ & 5 & {$[0,0,0,12,0,0,0,0]$} & {$[2,0,0,2,0,2,1]$} & PF \\
\hline KC71 & $\begin{array}{c}(20,104[0,0,0,0,2,0,2]][4-28-80-2616-592,3-32-72-200-480,3-32-72-200-480,2-8-36-96-288,2-28-36-96-288,2-8-16-72- \\
192,2-24-56-120-312,2-24-56-120-312,2-24-48-112-240,2-20-64-144-400])\end{array}$ & 7 & {$[0,0,0,0,0,8,4,0]$} & {$[0,0,0,0,2,0,2]$} & BFF \\
\hline KC72 & $\begin{array}{c}(20,104[0,0,0,0.2,0,2][4-32-64-208-416,3-32-64-192-384,3-32-64-192-384,2-8-40-80-288,2-8.40-80-288,2-8-16-80- \\
160,2-24-64-128-400,2-24-64-128-400,2-20-64-128-384,2-20-64-128-384])\end{array}$ & 6 & {$[0,0,0,0,0,8,4,0]$} & {$[0,0,0,0,2,0,2]$} & BFF \\
\hline $\mathrm{KC73}$ & 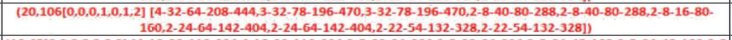 & 6 & {$[0,0,0,0,0,8,4,0]$} & {$[0,0,0,1,0,1,2]$} & $B F F$ \\
\hline $\mathrm{KC74}$ & $\begin{array}{c}(12,48[0,0,0,0,0,0,3][4-16-32-112-224,4-16-32-112-224,2-8-32-64-224,2-8-32-64-224,2-8-24-48-160,2-8-24-48-160,2-8 \\
24-48-160,2-8-24-48-160,2-8-16-48-96,2-8-16-48-96])\end{array}$ & 4 & {$[0,0,0,0,0,0,12,0]$} & {$[0,0,0,0,0,0,3]$} & BFF \\
\hline KC75 & $\begin{array}{c}(38,256[0,1,0,2,1,1,1][3-68-144-420-940,3-68-144-420-940,3-64-172-420-1116,3-64-172-420-1116,2-44-88-224-464,2- \\
44-112-232-644,2-44-112-232-644,2-40-104-276-696,2-40-104-276-696,2-36-136-288-840])\end{array}$ & 6 & {$[0,0,0,2,10,0,0,0]$} & {$[0,1,0,2,1,1,1]$} & PF \\
\hline KC76 & 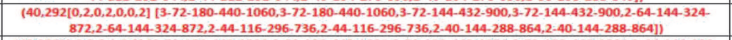 & 5 & {$[0,0,0,4,8,0,0,0]$} & {$[0,2,0,2,0,0,2]$} & PF \\
\hline $\mathrm{KC77}$ & $\begin{array}{c}40.296[1,0.20 .0,1,0.2][3-72-180-440-1096,3-72-180-440-1096,3-72-180-440-1096.3-72-180-440-1096,2-64-144-360- \\
880,2-64-144-360-880,2-44-116-296-736,2-44-116-296-736,2-44-116-296-736,2-44-116-296-736]) \\
\end{array}$ & 3 & {$[0,0,0,4,8,0,0,0]$} & {$[1,0,2,0,1,0,2]$} & PF \\
\hline $\mathrm{KC78}$ & \begin{tabular}{|c|}
$(40,288[0,0,4,0,0,0,0,2][3-72-144-432-864,3-72-144-432-864,3-72-144-432-864,3-72-144-432-864,2-64-144-288-864,2-$ \\
$64-144-288-864,2-40-144-288-864,2-40-144-288-864,2-40-144-288-864,2-40-144-288-864])$
\end{tabular} & 3 & {$[0,0,0,4,8,0,0,0]$} & {$[0,0,4,0,0,0,2]$} & PF \\
\hline KC79 & $\begin{array}{c}(36,224[0,0,1,0-4,0,1] \\
40-112-224-736,2-40-112-224-736,2-40-112-224-736,2-32-144-288-1024,2-32-144-288-1024])\end{array}$ & 4 & {$[0,0,0,0,12,0,0,0]$} & {$[0,0,1,0,4,0,1]$} & PF \\
\hline KC8O & $\begin{array}{c}(38,264[0,2,0,0,1,2,1][3-68-180-436-1148,3-68-180-436-1148,3-64-140-436-996,3-34-140-436-996,2-48-96-212-488,2- \\
48-96-212-488,2-48-116-276-648,2-48-116-276-648,2-36-128-280-872,2-36-128-280-872]) \\
\end{array}$ & 5 & {$[0,0,0,2,10,0,0,0]$} & {$[0,2,0,0,1,2,1]$} & PF \\
\hline KC81 & $\begin{array}{c}\left(19,91[0,0,0,0,0,3,1]\left[\begin{array}{l}4-30-68-204-480,3-28-66-180-448,3-28-56-170-368,2-20-58-124-374,2-18-56-122-350,2-18-56- \\
122-350,2-10-40-88-264,2-10-40-88-264,2-10-20-60-148,2-10-20-60-148])\end{array}\right.\right. \\
\end{array}$ & 7 & {$[0,0,0,0,0,7,5,0]$} & {$[0,0,0,0,0,3,1]$} & BFF \\
\hline KC82 & $\begin{array}{c}(38,268[1,0,1,0,2,0,2][3-68-180-468-1200,3-68-180-468-1200,3-64-172-456-1200,3-64-172-456-1200,2-48-96-212- \\
488,22-48-96-212-488,2-48-116-276-680,2-48-116-276-680,2-40-104-276-732,2-40-104-276-732])\end{array}$ & 5 & {$[0,0,0,2,10,0,0,0]$} & {$[1,0,1,0,2,0,2]$} & PF \\
\hline $\mathrm{KC} 83$ & $\begin{array}{c}(19,93[0,0,0,0,1,1,2] \\
{[4-30-68-216-496,3-28-78-184-526,3-28-68-184-436,2-20-58-136-400,2-20-48-126-300,2-20-48} \\
116-310,2-10-40-88-276,2-10-40-88-276,2-10-20-60-148,2-10-20-60-148])\end{array}$ & 8 & {$[0,0,0,0,0,7,5,0]$} & {$[0,0,0,0,1,1,2]$} & BFF \\
\hline $\mathrm{KC} 84$ & 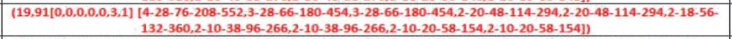 & 6 & {$[0,0,0,0,0,7,5,0]$} & {$[0,0,0,0,0,3,1]$} & BFF \\
\hline KC85 & $\begin{array}{c}(19,91[0,0,0,0,0,3,1]] \\
{[5-38-76-286-580,3-328-56-180-378,2-20-58-124-400,2-20-48-114-304,2-218-66-132-466,2-18-66-} \\
132-466,2-10-48-96-354,2-10-48-96-354,2-10-20-68-164,2-10-20-68-164]) \\
\end{array}$ & 7 & {$[0,0,0,0,0,7,5,0]$} & {$[0,0,0,0,0,3,1]$} & BFF \\
\hline KC86 & $\begin{array}{c}(36,232[0,0,2,0,2,0,2][4-72-188-5220-1388,4-472-188-520-1388,2-44-88-204-480,2-44-88-204-480,2-44-116-276-724,2-2- \\
44-116-276-724,2-36-108-296-816,2-36-108-296-816,2-36-108-296-816,2-36-108-296-816])\end{array}$ & 4 & {$[0,0,0,0,12,0,0,0]$} & {$[0,0,2,0,2,0,2]$} & PF \\
\hline KC87 & $\begin{array}{c}(19,93[0,0,0,0,1,1,2][5-38-88-290-672,3-28-78-184-562,2-20-58-136-426,2-20-58-136-426,2-20-48-136-320,2-20-48- \\
136-320,2-10-48-108-358,2-10-48-108-358,2-10-20-68-176,2-10-20-68-176]) \\
\end{array}$ & 6 & {$[0,0,0,0,0,7,5,0]$} & {$[0,0,0,0,1,1,2]$} & BFF \\
\hline KC88 & \begin{tabular}{|c}
$(38,248[0,0,0,0,4,0,0,1][3-68-144-356-904,3-68-144-356-904,3-64-140-400-916,3-64-140-400-916,2-40-108-252-608,2-$ \\
$40-108-252-608,2-40-108-252-608,2-40-108-252-608,2-36-128-280-800,2-36-128-280-800])$
\end{tabular} & 4 & {$[0,0,0,2,10,0,0,0]$} & {$[0,0,0,4,1,0,1]$} & PF \\
\hline KC89 & $\begin{array}{c}(38,252[0,0,2,0,3,0,1][3-68-144-388-924,3-68-144-388-924,3-64-172-420-1084,3-64-172-420-1084,2-40-108-252- \\
640,2-40-108-252-640,2-40-108-252-640,2-40-108-252-640,2-40-104-276-696,2-40-104-276-696])\end{array}$ & 4 & {$[0,0,0,2,10,0,0,0]$} & {$[0,0,2,0,3,0,1]$} & PF \\
\hline KC90 & $\begin{array}{c}(20,102[0,0,0,0.1,2,1][4-28-80-216-568,3-32-72-188-468,3-32-72-188-468,2-8-36-96-288,2-8-36-96-288,2-8-16-72 \\
192,2-22-54-126-314,2-22-54-126-314,2-22-54-126-314,2-22-54-126-314])\end{array}$ & 5 & {$[0,0,0,0,0,8,4,0]$} & {$[0,0,0,0,1,2,1]$} & BFF \\
\hline KC91 & $\begin{array}{c}36,216[0,0.0,0,6,0.0][4-72-144-432-1008,4-72-144-432-1008,2-36-108-252-684,2-36-108-252-684,2-36-108-252- \\
684,2-36-108-252-684,2-36-108-252-684,2-36-108-252-684,2-36-108-252-684,2-36-108-252-684]) \\
\end{array}$ & 2 & {$[0,0,0,0,12,0,0,0]$} & {$[0,0,0,0,6,0,0]$} & TF \\
\hline KC92 & $\begin{array}{c}(18,82[0,0,0,0,0,2,2][4-28-64-204-448,3-8-44-96-324,3-28-56-160-344,2-8-16-60-128,2-8-16-60-128,2-8-16-32-120,2- \\
20-48-112-308,2-20-48-104-272,2-18-56-120-364,2-18-56-120-364])\end{array}$ & 8 & {$[0,0,0,0,0,7,4,1]$} & {$[0,0,0,0,0,2,2]$} & EFF \\
\hline KC93 & $\begin{array}{c}(18,84[0,0,0,0,1,0,3][4-28-76-208-528,3-8-44-108-328,3-28-68-172-440,2-8-16-60-140,2-8-16-60-140,2-8-16-32-120,2- \\
20-48-124-324,2-20-48-124-324,2-20-48-116-296,2-20-48-116-296])\end{array}$ & 7 & {$[0,0,0,0,0,7,4,1]$} & {$[0,0,0,0,1,0,3]$} & EFF \\
\hline KC94 & $\begin{array}{c}\text { (18,84[0,0,0,0,1.0,3] }\left[\begin{array}{c}{[3-8-36-88-256,3-28-68-172-432,3-28-68-164-412,3-20-56-152-384,2-8-16-52-120,2-8-16-52-} \\
120,2-8-16-32-104,2-20-48-124-316,2-20-48-116-288,2-20-48-116-280]]\end{array}\right. \\
\end{array}$ & 9 & {$[0,0,0,0,0,7,4,1]$} & {$[0,0,0,0,1,0,3]$} & EFF \\
\hline KC95 & $\begin{aligned} &(18,82[0,0,0,0,0,2,2] {[3-8-34-96-246,3-28-56-168-362,3-28-56-168-362,3-18-64-146-432,2-8-16-50-128,2-8-16-50-} \\
&128,2-8-16-32-100,2-20-48-104-272,2-20-48-104-272,2-18-56-112-336])\end{aligned}$ & 7 & {$[0,0,0,0,0,7,4,1]$} & {$[0,0,0,0,0,2,2]$} & EFF \\
\hline KC96 & $\begin{array}{c}\begin{array}{c}(18,82[0,0,0,0,0,2,2] \\
{[3-8-36-88-244,3-28-56-168-364,3-28-56-160-336,3-20-56-140-368,2-8-16-52-120,2-8-16-52-} \\
120,2-8-16-32-104,2-20-48-112-300,2-18-56-112-328,2-18-56-112-328]]\end{array} \\
\end{array}$ & 8 & {$[0,0,0,0,0,7,4,1]$} & {$[0,0,0,0,0,2,2]$} & EFF \\
\hline KC97 & 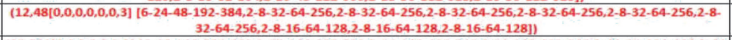 & 3 & {$[0,0,0,0,0,0,12,0]$} & {$[0,0,0,0,0,0,3]$} & BFF \\
\hline \multirow[t]{2}{*}{ KC98 } & 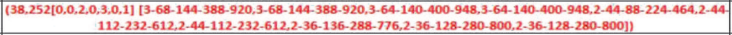 & 6 & {$[0,0,0,2,10,0,0,0]$} & {$[0,0,2,0,3,0,1]$} & PF \\
\hline & Total & 684 & & & \\
\hline
\end{tabular}

Figure 11. Ten link. $M=3$. Kinematic chains.

\section{References}

Agrawal V P and Rao J S 1987 Fractionated freedom kinematic chains and mechanisms. Mechanism and Machine Theory 22(2): 125-130 
Ambekar A and Agrawal V P 1986 On canonical numbering of kinematic chains and isomorphism problem: Max code. ASME Mechanisms Conference

Ambekar A and Agrawal V P 1987 Canonical numbering of kinematic chains and isomorphism problem: min code. Mechanism and Machine Theory 22(5): 453-461

Ding H, Huang Z and Mou D 2008 Computer-aided structure decomposition theory of kinematic chains and its applications. Mechanism and Machine Theory 43: 1596-1609

Eric A B and Chris H 2005 Efficient enumeration and hierarchical classification of planar simple-jointed kinematic chains: Application to 12- and 14-bar single degree-of-freedom chains. Mechanism and Machine Theory 40(9): 1030-1050

Huafeng D and Zhen H 2007 A new theory for the topological structure analysis of kinematic chains and its applications. Mechanism and Machine Theory 42(10): 1264-1279

Kong F G, Li Q and Zhang W J 1999 An artificial neural network approach to mechanism kinematic chain isomorphism identification. Mechanism and Machine Theory 34(2): 271-283

Marin G G, Casermeiro E M and Rodriguez D L 2007 Improving neural networks for mechanism kinematic chain isomorphism identification. J. Neural Process Lett. 26(2): 133-143

Mruthyunjaya T S 1984a A computerized methodology for structural synthesis of kinematic chains: Part 1 - Formulation. Mechanism and Machine Theory 19(6): 487-495

Mruthyunjaya T S 1984b A computerized methodology for structural synthesis of kinematic chains: Part 2 - Application to several fully or partial known cases. Mechanism and Machine Theory 19(6): 497-505

Mruthyunjaya T S 1984c A computerized methodology for structural synthesis of kinematic chains: Part 3 - Application to new case of 10- link, three-freedom chains. Mechanism and Machine Theory 19(6): 507-530

Mruthyunjaya T S 2003 Kinematic structure of mechanisms revisited. Mechanism and Machine Theory 38: 279-320

Mruthyunjaya T and Balasubramanzan H R 1987 In quest of a reliable and efficient computational test for detection of isomorphism in kinematic chains. Mechanism and Machine Theory 22(2): 131-140

Rajesh P S and Linda C S 2006 Structural synthesis of planar kinematic chains by adapting a Mckay-type algorithm. Mechanism and Machine Theory 41(9): 1021-1030

Rao A C 2000a Genetic algorithm for characteristics of kinematic chains. ASME J. Mech. Des. 122(2): 228-231

Rao A C 2000b Application of fuzzy logic for the study of isomorphism, inversions, symmetry, parallelism and mobility in kinematic chains. Mechanism and Machine Theory 35(8): 1103-1116

Rao A C 2004 Parallelism in planar kinematic chains (manipulators). Mechanism and Machine Theory 39: $1111-1122$

Rao A C and Raju V V N R P 2000 Loop based detection of isomorphism among chains, inversions and type of freedom in multi degree of freedom chain. ASME J. Mech. Des. 122: 31-42

Rao A C and Rao C N 1992a Loop based pseudo hamming values - 1. Testing isomorphism and rating kinematic chains. Mechanism and Machine Theory 28(1): 113-127

Rao A C and Rao C N 1992b Loop based pseudo hamming values - 2. Inversions, preferred frames and actuator. Mechanism and Machine Theory 28(1): 129-143

Rao A C and Varada Raju D 1991 Application of the hamming number technique to detect isomorphism among kinematic chains and inversion. Mechanism and Machine Theory 26(1): 55-75

Tang C and Liu T 1993 Degree code; a new mechanism identifier. ASME J. Mech. Des. 115(3): 627-630

Tischler C R, Samuel A E and Hunt K H 1995 Kinematic chains for robot hands-II, kinematic constraints, classification, connectivity and actuation. Mechanism and Machine Theory 30(8): 1217-1239

Uicker J J and Raicu A 1975 A method for the identification of and recognition of equivalence of kinematic chains. Mechanism and Machine Theory 10(5): 375-383

Yan H S and Hall A S 1981 Linkage characteristic polynomials: definitions, coefficients by inspection. ASME J. Mech. Des. 103(3): 578-584

Yan H S and Hall A S 1982 Linkage characteristic polynomials: assembly, theorems, uniqueness. ASME J. Mech. Des. 104(1): 11-20 